MA MAJOR RESEARCH PAPER

The Voice and the Void: The Scream in 1950s American Science Fiction Film

\author{
Melissa Hergott
}

\title{
Murray Pomerance
}

The Major Research Paper is submitted in partial fulfillment of the requirements for the degree of Master of Arts

Joint Graduate Program in Communication \& Culture Ryerson University - York University

Toronto, Ontario, Canada

5 May 2010 
Table of Contents

Chapter One: American Science Fiction Film and the 1950s.................................................. 2

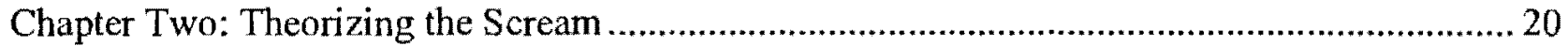

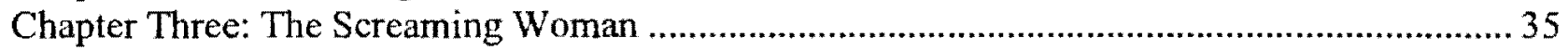

Chapter Four: The Screaming Man..................................................................................... 51

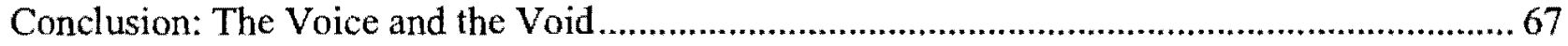

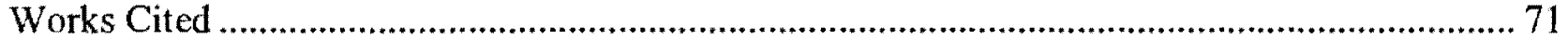

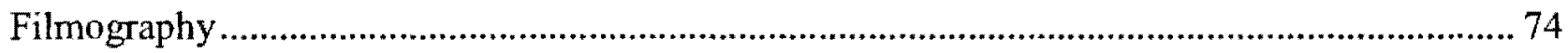




\section{Chapter One: American Science Fiction Film and the 1950s}

In the United States, science fiction film rose to prominence as a critically recognized genre in the 1950s, a decade fraught with cultural complications and contradictions and also inspired by optimism and upward trajectory. Warren Susman characterizes the period as one marked by a "dual consciousness," a time when "the fulfillment of our sweetest desires [led] inevitably to the brink of danger and damnation"; the fifties, he writes, was an age of anxiety as much as it was a time of abundance, freedom, and possibility (30). For historian David Halberstam, while a retrospective examination of the decade suggests to some a "slower, almost languid" pace, social ferment "was beginning just beneath this placid surface" (ix). Throughout the decade, notions of national security played out in conflicting ways that traversed both the public and private spheres. Science fiction, a genre that coincided with massive industry changes that saw the development of a sizable low-budget, teen-oriented independent sector, resonated deeply with such opposing and anxiety-laden articulations of both public and private security. While most previous discussions of the genre tend to focus on such concerns in their public dimension (particularly as related to political unease during the Cold War), what follows will address sci-fi's depiction of anxieties in that other, more private realm of American society, particularly in relation to the expression of gender, sexuality, and desire.

Cold War politics, the postwar consumer boom, re-entrenchment of family values and suburban home life, and industry upheavals in Hollywood are all important for understanding what is now thought of as the golden age of American science fiction film. These socio-political factors contextualize the genre's rise to prominence, its defining stylistic and thematic characteristics, and its treatment of gendered subjectivity. As we will see, while some science fiction films of the 1950s engaged or challenged cultural rhetoric related to expected norms of 
gendered behaviour, for the most part these films upheld the era's return to more traditional gender roles for men and women, an observation which has been taken up in the critical literature, particularly within feminist film scholarship. However, within this body of films exists a common and recurring convention that has been largely neglected by science fiction film scholars, one that warrants further study due to its implications for understanding the return to domesticity in the American postwar period. This filmic convention is the scream, a visual and aural articulation of fear expressed mostly by women (but also, and just as importantly, by men). Far from being a mere cheap gimmick employed by filmmakers alongside special effects and insatiable monsters, the scream provides valuable insight into the domestic ideologies that prevailed during the 1950s.

\section{Postwar American Culture and Hollywood}

While the atomic bombing of Hiroshima and Nagasaki in 1945 marked the conclusion of the War in the Pacific, feelings of victory soon chilled to grave concern over the potential risks of harnessing nuclear energy. For example, American concerns about radiation poisoning were exacerbated after news leaked that the Soviets had successfully tested an atomic bomb in 1949 (Halberstam 26). With both countries engaged in an arms race of which the outcome remained uncertain, Americans were uneasy. Both the United States and the Soviet Union would continue efforts toward building a hydrogen bomb in widely publicized efforts that heightened national worries of the potential for nuclear warfare. Moreover, the expansion of the Eastern Bloc by the Soviet Union increased fears on behalf of the U.S. government that communism was a real threat to American national security. On home turf, Senator Joseph McCarthy led public witch hunts intended to purge suspected Communists from government positions, sowing distrust of anyone considered Left leaning, subscribing to radical politics, living a sexually "deviant" (i.e. 
homosexual) life, or holding any view considerable as un-American (49-59). Adding to these fears was the Soviets' launch of its satellites Sputnik and Sputnik II into space in 1957, which signaled the reality that the East was surpassing the West in technological and scientific advancement (624-627).

Politics aside, the fifties were a time of unparalleled progress, fueled by postwar affluence, the growth of consumerism, and the unprecedented development of new technologies. As men and women married earlier in their twenties, Levittown-inspired suburban communities chockful of modest one-storey ranch houses sprang up around the country to accommodate young families looking to settle down (Halberstam 134-37). Commonplace mass migration out of the cities and into suburban communities led to "a worldview, a value system centred on the family" (Errol Vieth 76). Shopping malls, with their one-stop-shop appeal, were built on the outskirts of these areas and quickly claimed hold over the family pocketbook. Credit cards eased anxieties around consumer spending and created economic optimism. Fast food chains such as McDonald's and roadside motels such as Holiday Inn served families on their way to such attractions as the newly developed Disneyland in Anaheim, California (see Halberstam 157-59, 173-79, and Karal Ann Marling 93-97). The appeal of such travel was made possible by the growing interstate highway system (thanks to the 1956 Highway Act) and the increased availability of affordable American automobiles manufactured by the likes of GM, Ford, and Chrysler. Advertising wooed the so-called "Happy Housewife" with kitchen gadgetry and matching pastel appliances that went out of style almost as soon as they were hailed as cuttingedge. Kitchen innovations such as Tupperware, Saran Wrap, microwaves, and Teflon, along with photo-essay cookbooks, frozen "TV dinners," minute rice, processed cheese, and powdered drink and soup mixes all made food preparation and storage quicker and simpler than in previous 
generations (see Marling 202-222 and William H. Young and Nancy K. Young 96-104). The DoIt-Yourself movement ushered in the popularity of power tools, paint-by-numbers, and model train sets that, along with television, encouraged leisure activities that took place within the home (Marling 51-60). All of these changes made middle-class life in the 1950s brighter, faster, easier, more affordable, and more efficient.

The decade also saw the enforcement of the "cult of domesticity," to use Elaine May's term, as the nuclear family prevailed as the ideal model for domestic bliss. As May argues, domestic ideology during the 1950s was a response to fears rallying around gender, economics, and political and cultural crises that emerged after WWII (11). These fears, May explains, included worry that the conversion to a peacetime economy would lead to another depression; anxiety that peace had merely marked the beginning of a period of fragile international relations; and, of course, ambivalence towards atomic discovery (22-23). In light of these concerns, she argues, "the family seemed to be the one place where people could control their destinies and perhaps even shape the future" (24).

The policing of sexuality during this time was informed by a logic that equated heterosexual marriage with maturity and responsibility while all other behaviour was seen as deviant, weak, and irresponsible (May 94). Moral weakness, as it was associated with sexual degeneracy and communism, could only be controlled through the stability of the nuclear family: that is, a sexually submissive and competent housewife and an assertive husband in control of the household. Experts wamed that the employment of single women would lead to sexual promiscuity while that of married women would lead to unsupervised homes, both of which led to the weakening of the national moral fibre (99). Pronatalism flourished along with the baby boom. Popular culture advocated the view that motherhood was at the heart of female sexual 
fulfillment and identity, and fatherhood "became a new badge of masculinity and meaning for the postwar man" $(142,146)$. Men and women directed their energies into securing domestic stability through marriage, and ignored or suppressed desires for alternative lifestyles that went against the grain.

The return to domesticity illustrates the conservative cultural rhetoric that dominated throughout the decade. Despite the growth of consumer optimism that instilled national pride in American craftsmanship, fresh ideas, and new possibilities, conformism to certain ideals nevertheless prevailed; any viewpoint or lifestyle existing outside the realm of white, patriarchal, heterosexist capitalism was considered suspect. Race relations, for example, pointed to an America not yet willing to look beyond the firmly drawn lines between white and Black experience. Racism still dominated public attitudes towards minorities even as the Supreme Court ruled in favour of desegregation in public schools in the 1954 landmark case of Brown v. Board of Education. The enrollment of nine Black students in Little Rock Central High in Arkansas in 1957 was met with resistance - the National Guard, in fact, as hired by governor Orval Faubus - that required President Eisenhower to dispatch U.S. troops as escorts to ensure their safety on campus (Halberstam 667-698). Social attitudes towards racial diversity were not as quick to catch up with legislation: racial minorities were not often portrayed in advertising, film, or television programming and black Americans still faced discrimination in housing, employment, and day-to-day relations. Within this political, social, and cultural framework, the notion of security was understood as necessary not only in terms of protecting the United States from external Soviet threats, but also as of way of ensuring the moral fibre of the nation would not be weakened by depravity, especially in relation to sexuality and gender. 
Hollywood was finding itself in a state of transformation. The 1948 Paramount Decree ended the monopoly over exhibition held by the five major studios - Warner Bros., Paramount, Loews-MGM, $20^{\text {th }}$ Century Fox, and RKO. Divesting themselves of their exhibition holdings now meant that these companies could no longer control when, where, or for how long films were screened, a change which negatively affected the security of box-office profits and leveled the playing field between the major and minor studios (Vieth 102). This change led to a breakdown of the studio system that had been so firmly established in prior decades, with production now restricted to fewer higher budget " $\mathrm{A}$ " productions made by specialized staff who worked in specific areas and saw a film through from start to finish. This attention to better quality films was also part of a strategy to court audience pocketbooks, necessarily in light of lagging box-office returns. In the early 1950s, the film industry found itself struggling with two very serious issues concerning viewership: the decline of film attendance and the fragmentation of audiences. Suburban migration and the competition of household television are credited as the major culprits for the drop in viewership. As young men and women moved from urban centres into the suburbs to start families, downtown city cinemas suffered a loss of profits. Moreover, the rise of television purchases kept parents and children firmly planted in their living rooms. Box office statistics from the period indicate that film attendance fell drastically from the mid-forties well into the fifties, with admissions dropping by approximately half between 1946 and 1956 (Lev 7). The instability that studios faced as a result of the anti-trust decision and the decline of viewership was only further exacerbated by the House Committee on Un-American Activities (HUAC), whose investigations into communist activities and allegiances within Hollywood caused widespread unease as the realities of the blacklist loomed near (67). Censorship of filmic content was also firmly entrenched by the 1950s and would show no sign of easing off until the 
latter half of the decade when a revision in 1956 would allow for the careful treatment of such previously banned topics as pregnancy, interracial marriage, abortion, and prostitution (Young and Young 201). The application of the Motion Picture Production Code by the Production Code Administration had been the industry's mode of self-regulation since 1934, with the group continuing to act as liaison between Hollywood and government censorship boards to ensure the morality of onscreen material, much to the chagrin of writers and directors (Lev 86). With these many pressures placed on the film industry, studios continually worked to find ways to maximize profits and to foster artistic creativity while appeasing outside groups suspicious of its internal affairs.

In order to lure audiences back into theaters, film companies experimented with a variety of new technologies in the early fifties. Recognizing the limitations of television-the small viewing area, the lack of colour, the poor sound and image quality-studios produced and marketed big-budget epics and musicals as spectacles that could not be experienced on the small screen. Widescreen processes such as CinemaScope, Panavision, Todd-AO, and VistaVision, colour methods such as Technicolor and Eastmancolor, and novelties such as 3-D and Cinerama were all used (to varying degrees of success) to draw viewers back to the cinema (see Lev 107125 and Murray Pomerance 11-12). Studios recognized that earlier understandings of the American film audience as a mass, homogeneous entity no longer applied to postwar consumer tastes and, in response, began developing and marketing films to different types of viewers in order to capitalize on the changing marketplace.

\section{The Golden Era of Science Fiction}

Within this undeniably rich and provocative historical context, the science fiction film found its niche, capturing the imaginations and capitalizing on the diffuse and widespread 
anxieties, hopes, and fears of Americans. While the genre finds its roots in earlier decades, the 1950s saw the release of many American-made films now considered genre classics along with a sizable number of low budget " $\mathrm{B}$ " films that led to the formal critical recognition of what is now known as science fiction film. Bill Warren credits the 1952 re-release of the 1933 feature King Kong as one of the biggest influences propelling the genre into audience popularity in addition to inspiring a sizeable number of "creature-features" throughout the decade (xiv). Victoria O'Donnell suggests several other factors as fuelling the sci-fi fad: first, the news of the Soviets testing an atomic bomb in 1949; secondly, the success of science fiction literature by such writers as Robert Heinlein and Ray Bradbury; and, lastly, notable audience approval of the handful of science fiction films made in 1950 and 1951 that encouraged Hollywood production companies to follow in pursuit of profits (170). Until a decline near the end of the decade, science fiction cinema enjoyed enormous success, with reports estimating that the number of features and shorts totaled nearly five hundred worldwide between 1948 and 1962 (169), with close to 200 of those made in the United States between 1950 and 1959 (Christine Comea 71n1). Adult sensibilities were catered to early in the decade by science fiction films such as Destination Moon (1950), Rocketship X-M (1950), The Day the Earth Stood Still (1951), and The Thing from Another World (1951). While it is true that high-budget science fiction features continued to be released throughout the fifties, studios also released double-feature low-budget "B" flicks to sell to the growing drive-in market, effectively shifting the target audience of sci-fi from adults to young people. Restless teenagers with cash to spend, and eager for refuge or a dark venue for sexual experimentation, sought out films such as The Beast with a Million Eyes (1955), It Conquered the World (1956), Invasion of the Saucer Men (1957), and Attack of the Puppet People (1958). Because drive-in theaters did not screen first-run pictures, but offered 
instead second- or third-run films or lesser quality low-budget fare produced specifically for this market, cheap science fiction " $\mathrm{B}$ " films became part of drive-in culture just as the content of these films became more about the horrific or monstrous elements an adolescent audience could relish and filmmakers therefore aimed to exploit (Vieth 115).

With the exception of RKO--which folded in 1953-all of the major studios contributed to the science fiction boom in the 1950 s, as did their smaller contenders, Columbia, Universal, and United Artists (Vieth 117-119). Smaller film studios such as Allied Artists, Lippert Pictures, and American International Pictures also made significant contributions to the genre during this period (119-120). George Pal, Robert Wise, and Howard Hawks paved the way in the first years of the decade, establishing genre conventions and trends that would be imitated by countless other films to come with such features as Destination Moon, The Day the Earth Stood Still, and The Thing from Another World. Other directors such as Jack Arnold, Roger Corman, Bert I. Gordon, Byron Haskin, Kurt Neumann, Don Siegel, Fred Sears, and others continued throughout the fifties to make audience-friendly films that appealed to the public imagination and played off cultural and political fears related to the Cold War-era paranoia of Soviet nuclear threats, radioactive fallout from atomic testing, and "what-if" scenarios that re-imagined UFO sightings of the late 1940 s as precursors to actual alien invasion.

\section{The Science Fiction Style}

Due to the overlap of these films with other equally permeable 1950s genres-the horror film, the fantasy film, the melodrama - the boundaries of sci-fi are often not as easily drawn as one might assume. Horror, in particular, shares important thematic elements and visual conventions with science fiction, especially the dual presence of the hideous monster and the screaming woman. Indeed, many science fiction films of this period share enough in common 
with horror to warrant hybrid categorization, including titles like The Thing from Another World, The Fly (1958), and The Creature from the Black Lagoon (1954) (for further discussion on the distinction between horror and sci-fi, see Bruce Kawin, "Children of the Light"). Scholars often distinguish between science fiction and horror in terms of the different approaches the genres take towards their shared elements. This is particularly the case with each genre's inclusion of inhuman or otherwise horrific creatures. Margaret Tarratt argues that science fiction aliens represent sexual urges and often possess phallic qualities (either symbolically or literally). Films such as Forbidden Planet, Tarratt claims, contain monstrous creatures - the monster from the id, for instance-that represent uncontrollable male sexual desire (347-50). Conversely, monsters within the horror film symbolize a much wider range of social repressions as objects of horror. Robin Wood argues that the figure of the monster within the genre represents what is oppressed and figured as the Other in society, including that which is not monogamous, heterosexual, bourgeois, patriarchal, or capitalist. For Wood, in addition to representing a "generalized sexual threat," the horror monster also invokes the Otherness of female sexuality, the proletariat, other cultures and ethnic groups, alternative ideologies, bi- and homosexuality, and children (201). Thus, while horror and science fiction may be said to claim hold over similar narrative conventions, how these elements are taken up varies greatly in each genre (the implications of which difference will be taken up in greater detail in Chapter 3).

Many scholars answer the question, "What is Science Fiction Film?" by breaking it down into its recognizable themes, categories, or subgenres: space travel to the moon or other planets, mutation caused to humans or other life forms by way of radiation, alien visitation or invasion, the end of the world, and the presence of science as the explanatory thread that either introduces a problem or solves it (or both). Some writers characterize sci-fi by its emphasis on the 
relationship between fear of the unknown and the calming rationality of knowledge and science. Warren, for instance, defines science fiction film as "a fantasy film in which the fantastic element is rationalized as being explicable in scientific terms" ( $\mathrm{x}$ ). John Baxter argues that science fiction films generally fall into one of two types: those that feature the loss of personal individuality - such as social control, psychological control, or electrical domination of the mind—and those that focus on the threat of knowledge that "expresses the universal fear all men have of the unknown" (11). Baxter emphasizes the formulaic nature of science fiction plots, noting that sci-fi film is a "sensuous medium," a genre which has "the quality of ritual" (12). Warren echoes this sentiment, arguing that part of the ritualistic aspect of these films lies in their visual and narrative conventions (xiii). Susan Sontag best summarizes the typical narrative structure of the fifties sci-fi film in her essay "The Imagination of Disaster," humorously providing a handful of typical scenarios that correspond to a film's budgetary abilities or constraints (209-212). However, in contrast to Warren and Baxter, Sontag argues that at the heart of the 1950 s science fiction lies a fascination with "the aesthetics of destruction, with the peculiar beauties to be found in wreaking havoc, in making a mess" (213). In her view, the science fiction film is not about science at all; rather, the genre permits one to find temporary enjoyment in suffering and disaster:

We may, if we are lucky, be treated to a panorama of melting tanks, flying bodies, crashing walls, awesome craters and fissures in the earth, plummeting spacecraft, colorful deadly rays; and to a symphony of screams, weird electronic signals, the noisiest military hardware going, and the leaden tones of the laconic denizens of alien planets and their subjugated earthlings. (213) 
For Sontag, part of the pleasure of watching science fiction film is that it allows one to "give outlet to cruel or at least amoral feelings" (215). The appeal of the genre is that it permits one to vicariously "participate in the fantasy of living through one's own death and more, the death of cities, the destruction of humanity itself" (212).

The look and feel of science fiction is indebted to a variety of other aspects including casting and special effects. Sci-fi directors often cast unknowns in leading and supporting roles, although some actors found their calling as genre favourites. John Agar, Paul Birch, Richard Carlson, Faith Domergue, Russell Johnston, Hugh Marlowe, Jeff Morrow, Rex Reason, and Barbara Rush are examples of repeat personnel throughout the decade. While fame and fortune lay just out of reach for the typical sci-fi actor, a small number of players found later success within the mainstream film industry, following early roles in low-budget films. Tarantula (1955), for instance, features a young Clint Eastwood in an uncredited role near the end of the film as an U.S. Air Force pilot while The Blob (1958) stars Steve McQueen in his first movie role, fighting against a gelatinous alien. Big-name Hollywood stars did not usually make the crossover into science fiction, although there are a few exceptions to this rule, such as Forbidden Planet (1956), which included Walter Pidgeon and Anne Francis and On the Beach (1959), which featured the ensemble cast of Gregory Peck, Anthony Perkins, Fred Astaire, and Ava Gardner. Vieth argues that one reason for casting unknowns is because the standard alien creatures themselves-often referred to as BEMs or bug-eyed monsters-functioned as stars, as evidenced by illustrated movie posters that emphasized the gory monster over its human counterparts (38).

Another reason for casting unknowns may be explained in purely financial terms. The drastically reduced budgets of sci-fi films meant that little money was available for special effects, props, and sets-or for big-name stars. Lastly, the lack of famous actors helped to 
suspend disbelief in plots with already absurd premises; familiar faces tend to bring audiences back to reality while those of unrecognizable actors help one to better engage with the story without distraction of star power. Perhaps resulting from this common practice of casting unknown personnel, many critics (Warren, Baxter, and O'Donnell among them) have since complained that male and female leads lacked depth or substance, poorly portraying characters that were interchangeable or even forgettable. While it is not difficult to disagree with these sentiments, it is important to note that character development was usually not integral to the film. Films often focused on imaginative elements and creative special effects, with characters only existing as vehicles for advancing the story. As Baxter explains,

Pragmatic, idealistic, sustained by the mystique of technology and a belief in the desirability of mathematical order in human affairs, science fiction's concern is not with individuals but with movements and ideas. Generally its characters have no function except as symbols in the writer's chessboard development of his premise. (7)

The distinctive look of these films is marked by a gray, flat, and realistic tone reminiscent of a semi-documentary style made popular in crime and espionage films of the previous decade (Warren xiii). While most films were "restrained and visually bland," writes O'Donnell, the genre benefitted from a handful of high-budget features that made use of well known science fiction illustrators for backdrop construction, included documentary footage to enhance realism, sprang for the latest 3-D technology to terrify crowds, and even borrowed equipment from university science labs and the National Guard (171). As J.P. Telotte puts it, "The very technological underpinnings of this form contribute fundamentally to its identity" (28). Vieth argues that special effects assume star status in fifties sci-fi, as they are integral to the mise-enscène in order to "transmogrify the unreal into the real" and suspend audience disbelief (39). 
George Pal and Ray Harryhausen were two of the most significant special-effects technicians to contribute to the science fiction genre. Pal's contributions to Destination Moon, When Worlds Collide (1951), and War of the Worlds (1953) were recognized by the Academy of Motion Picture Arts and Sciences, which awarded each film an Oscar for Special Effects. Harryhausen brought his expertise with stop-motion animation to such films as The Beast from 20,000 Fathoms (1953), It Came from Beneath the Sea (1955), Earth vs. the Flying Saucers (1956), and 20 Million Miles to Earth (1957). Vivian Sobchack argues that "the major visual impulse of all SF films is to pictorialize the unfamiliar, the nonexistent, the strange and the totally alien" in order to secure the viewer's belief rather than suspend disbelief (Screening Space 88). Special effects invoke a heightened sense of realism within the films by translating the unknown into that which is visually tangible.

\section{What Sci-Fi Cinema Means}

Scholars have approached science fiction films of the fifties from many different angles in order to understand their purpose and function within American society. Warren argues that references to Communist threats or radiation in science fiction were "not a form of nuclear paranoia, merely cheap and simple plotting" (xiii). In other words, the proliferation of mid- and low-budget " $B$ " films during the fifties--with their exaggerated monsters, miniature models of rocket ships, and stock footage- was more a way to court the wallets of teens and adults looking for ninety minutes (or less) of escapism and was not a direct reflection of the nation's fears. This view is not a popular one and has been countered by many scholars interested in unraveling the deeper implications of sci-fi's thematic and visual preoccupations. Baxter argues that the sci-fi genre tends to "endorse the political and moral climate of its day," a common argument among sci-fi enthusiasts (12). Vieth, building on this view, maintains that these films were not only 
mass entertainment but also pro-American military propaganda. He writes, "There are elements that persuade audiences that the military and the military culture are both the savior of the United States ... and a worthwhile expenditure in the national budget" (74). Sontag argues that while sci-fi is "strongly moralistic," the focus is shifted away from human problems to those having to do with technology and the artifacts of science: "A greater range of ethical values is embodied in the décor of these films than in the people" (216). More broadly, Sontag writes, "The films reflect world-wide anxieties, and they serve to allay them" (225). But while it may be said that science fiction engages with artifacts and institutions such as the military, scientific knowledge, and technology, it may also be argued that the films have much to reveal about gendered subjectivity and desire. This is especially so given the reinstatement of strict gender roles for men and women that occurred during the decade, including the domestication of women and the affirmation of masculine authority.

Science fiction cinema of the 1950s is a male-dominated genre both on- and offscreen in its storytelling and design, often featuring crews of scientists, astronauts, governmental agents, and military crews that are noticeably absent of women. Cornea argues that the accomplishments of women in such films, insofar as they are shown, are often overshadowed by romantic involvements with male heroes or by the achievements of other male characters, and are thus diminished (50). Cornea also notes that the hideousness of the alien and the degree to which we are menaced by it are more often than not directly proportional to the independence or sexual allure of the leading female character (50). Parts for women were limited in this genre. Bonnie Noonan reads female scientist characters as embodying the extreme gender possibilitiesspanning from vixen to spinster - that were available to women during the decade, noting the struggle for balance between the two opposing poles that these women must attain (50). For 
Noonan, gendered readings of 1950 s science fiction films can be used to explore several themes, including expectations of the dutiful wife or fiancée, the importance of motherhood, relationships between women, the effects of women in the workplace, the limits placed on female power, the boundaries of masculine identity, and the nature of acceptable bonds between men (156-58). In addition to these themes, Cornea views the genre as overdetermining the family unit, with representations of father/son and father/daughter relationships leaning towards an ambivalent position on the ways in which societal changes—such as technological development and corporate capitalism-affected the domestic realm (57). In general, she argues, while in portraying female scientists and lab assistants sci-fi films of the 1950s engaged with social changes that granted women increased access to the public sphere, these narratives were largely unable to imagine happy or viable alternatives to traditional social structures such as the domestic environment (57).

Of particular interest is the genre's treatment of sexuality and desire. As noted above, character development was often overlooked in order to emphasize the gimmick: the arrival of a oddly shaped flying saucer or rocket ship on the outskirts of town; the effects of mind-control and bodily takeover by strange unknown visitors; the giant grotesque insect, arachnid, or cephalopod with a taste for humans; the effects of atomic fallout on humans and nonhuman animals; the onslaught of violent alien war machines; the friendly robot led astray by malevolent alien influence; the launch of a rocket into the depths of outer space; or the first steps by humans onto unexplored foreign planets. The introduction of love stories into the plot of such films often feels obligatory, even forced, and is treated as secondary to problems (such as a uncontrollable monster wreaking havoc) and their solutions (deployment of the military). Sobchack reflects on this phenomenon in her brilliant essay, "The Virginity of Astronauts: Sex and the Science Fiction 
Film," characterizing science fiction film by its notable absence of biological sexuality and desire, particularly as associated with women. She argues that, barring a few exceptions, sex constitutes a "negative topic" in the genre, an absence which "surrounds a purposeful—if unconscious-repression" (103). Human sexual dramas, Sobchack continues, "tend to be safe and chaste in their dramatization and peripheral to narrative concerns... . One gets the feeling that they are included either to satisfy the vague demands of formula or to answer the unspoken charges of homosexuality which echo around the edges of the genre" (105). In Sobchack's view, female biological difference is de-emphasized by "sensible and functional attire, by rational occupations, and by the unprovocative, 'fulfilled' sexuality of a peripheral and occasional wife and mother" (105). Likewise, Tarratt argues that while science fiction outwardly deals with "science," inwardly these films reconcile the repressed sexual desires of the individual. Tarratt draws attention to several common tropes of sci-fi that highlight this theme of sexual repression as it pertains to men, including: space travel that is accompanied by the sexual frustration of the all-male crew, asexual scientists with an absolute dedication to knowledge, and male heroes who possess controlled sexual drives (350). For Tarratt, as with Sobchack, science fiction films derive their structure from Freudian psychoanalysis and "arrive at social comment through a dramatization of the individual's anxiety about his or her own repressed sexual desires, which are incompatible with the morals of civilized life" (347).

Overall, then, it may be argued that science fiction film operated by erasing woman's presence, woman's accomplishment, and woman's sexual feeling while emphasizing the stoicism and cool rationality of men, whose asexuality permitted an undistracted commitment to the furthering of scientific advancement and the acquisition of knowledge. Within this framework exists perhaps the most intriguing and yet least discussed aspect of these films, a particular 
dramatic, visual, and aural event that is as much part and parcel of the science fiction milieu as underlying Cold War anxieties, colourful mattes featuring the rocky landscapes of other planets, lush orchestral scores punctuated with eerie moans of the electric Theremin, and the headstrong scientist looking for answers. Such moments occur at the height of climactic tension, rousing the viewer seconds before the monster strikes or the alien attacks, piercing the air with a shrill sound as predictably familiar as it is sudden and shocking. That sound, heard again and again across many of sci-fi's canonical films and paired with that accompanying look of wide-eyed and expectant fear, is the high-pitched shriek of the woman screaming. It is her voice to which we now turn: to her fears, her presence, and her vocal accomplishment. 


\section{Chapter Two: Theorizing the Scream}

The screaming woman not only forms a striking point of attention in many sci-fi narratives but is among science fiction's most remarkable and memorable conventions; in fact, few films of the 1950s exist without her.

Mikel Conrad's The Flying Saucer (1950), one of the first features to treat the subject of UFOs, even goes so far as to open with a scream. Immediately following the credits, a flying saucer is seen and heard whizzing through the air, followed by a montage of newspaper headlines cut with shots of anxious citizens looking and pointing towards the sky, a trademark shot in 1950s alien-invasion epics. As the title music abruptly stops, cut short by the asynchronous sound of the saucer, we are treated to a close-up of a middle-aged woman facing sideways and gazing upwards, framed by a clear sky and cumulous clouds. Slowly, she turns to face the camera and, as her eyes meet ours, she suddenly begins to scream over and over again until, without warning, she runs out of frame. Is she reacting to the vessel coming from afar, or to us, passively watching? Conrad's screaming woman is but one example of many who will appear again and again throughout the decade in the form of happy housewives (It Conquered the World), dutiful daughters (The Man from Planet X [1951]), concerned mothers (The Day the Earth Stood Still), loving girlfriends (Invasion of the Body Snatchers [1956]), marine biologists (It Came from Beneath the Sea), physicians (Invaders from Mars [1953]), graduate students (War of the Worlds), research scientists (This Island Earth [1955]), lab assistants (Tarantula), secretaries (The Invisible Boy [1957]), and school teachers (It Came from Outer Space [1953]). But while Conrad uses his nameless shrieking woman as pure gimmick, inserted into the first reel of the film without reason or explanation—and, as it is worth noting, never to be seen or heard from again - it is more typical of the genre to integrate the scream seamlessly into the 
narrative. Nevertheless, as it appears in both Conrad's film and others, the scream functions alongside the repulsive creature or the stream-lined rocket ship as a spectacle to behold for and unto itself, as a moment in which visual and aural elements come together to shock the senses and awaken the emotions.

\section{Sound, Speech, and Vocal Expression}

According to sound theorists, film sound and image are inextricably linked in a hierarchical partnership that relies on the perception of visual elements for the making of meaning. As John Belton explains of sound and image, "The two are apprehended together, though sound is often perceived through or in terms of the image and, as a result, acquires a "secondary status"" (64). Sound is usually understood through an image and not on its own accord. Hence Alberto Cavalcanti's view that "while the picture is the medium of statement, the sound is the medium of suggestion" (109). Images provide a sense of what is true (and what is there) while sound fine tunes them. Through its power of suggestion, sound can appeal directly to the senses by reaching the unconscious in ways that the visual effect cannot.

Some early theorists of film sound posited a Romantic dualism between thought and

feeling. For example, Cavalcanti writes that noise "speaks directly to the emotion... . Pictures speak to the intelligence. Noise seems to by-pass the intelligence and speak to something very deep and inborn" (109). If we break down film sound into musical score, sound effects, and dialogue, again a hierarchy of perception emerges, with language most dominant. As sound theorist Michel Chion claims, "There are voices, and then everything else" (5). Occupying a shifting position on the continuum between non-vocal sound and speech lies one of cinema's most notable conventions, a type of sound that is simultaneously vocal and non-linguistic, one that acutely expresses emotions that exist just outside the reach of language. This might be 
called "sensational" or "feelingful sound." It can be equally an effect unique and particular to the mouth that bears it and a sound that loses its origin in a kind of generalized multiplicity. Such "feelingful" sounds occur during moments of uncontrollable bodily convulsions, spasms, or ecstasy - the latter of which, as Linda Williams explains, refers not only to "sexual excitement or rapture" but also to insanity, bewilderment, sadness, terror, and fear ("Film Bodies" 4). Spasmodic feelingful sounds include sobs of anguish or grief, cries of pleasure or disgust, gasps of shock, or growls of anger. These noises move beyond what can be expressed in words into the realm of interior expression of the intangible, elusive, or incomprehensible. As performance theorist Emil Hrvatin writes, "The voice is able to transport bodies and spaces where they literally cannot move to. The voice defines a space which is invisible" (82).

The scream is a particularly striking manifestation of this convention, an image-sound pairing that swiftly traverses genre boundaries to provoke, tantalize, and frighten audiences with its strikingly piercing effect and its familiarity. In a discussion of the "interior monologue" in film, Mary Ann Doane understands the voice as affecting the viewer in ways the image cannot: The voice and the body are represented simultaneously, but the voice, far from being an extension of that body, manifests its inner lining. The voice displays what is inaccessible to the image, what exceeds the visible: the "inner life" of the character. The voice here is the privileged mark of interiority, turning the body "inside-out" (168).

Doane's inner monologue is the scream waiting for release. The scream is the body turned "inside-out," the viscera exposed and put on display: the knotted stomach, sweaty palms, dry mouth, and goose-pimpled flesh, not to mention the cold sweat gathering at the base of the neck and upon the temples, that lump in the back of the throat, and the rush of adrenaline that peaks as the heart throbs loudly, nearly bursting through the chest. These bodily symptoms reek of fear, 
anxiety, and the sense that something is —or is soon to be-terribly wrong, all exposed in that moment when the scream is released: the vocal chords tighten, the throat spasms, and a shrill shriek takes life with incredible force. In many film genres, especially horror, science fiction, and film noir, the scream has become an iconic convention that is anticipated by audiences at the height of key characters' dramatic tension or fear, at a moment when the film peaks with new narrative revelations and visual surprises. It appears across genres to the delight of expectant viewers seeking resolution to frightening and contradictory images both violent and erotic. As sound theorist Philip Brophy explains, "The scream rings loud as if to give a waming, a message, a statement - but all it does is thrill us, raising the hair on the back of our necks and stimulating the pubic forest of our confused desires" (55). The scream exists on the border between pleasure and danger, a distinction which remains nebulous at best given that some of the thrills of watching science fiction (and other genres) arise from and are directly proportional to the nature of the unspeakable terrors inflicted upon the heroine. Her scream of fear accordingly becomes our (voyeuristic) cry of pleasure.

\section{The Look and Sound of the Scream}

Within the 1950 s science fiction canon of revolting monsters, malicious alien forms, overgrown radioactive insects, and impending doomsday threats, the scream-what Brophy deems "that corny, camey, carnivale cry" (52)_is a recurring and spectacular feat, one that " $B$ " directors were want to exploit with as much unyielding fervour as they brought to the aforementioned provocative terrors. As Barbarella's (1968) eponymous heroine (Jane Fonda) duly proclaims, upon hearing cries of pleasure and anguish following her arrival in the decadent city of SoGo, "That screaming ... Good many dramatic situations begin with screaming!" 
The screams of women that pepper 50s sci-fi are either indications of diffuse fear or direct responses to known or suspected threats of danger or harm. Audiences expect that the scream will contain and refer to clearly established visual and aural elements: in most cases, there is a diegetic provocation before the character's mouth opens and we hear the shriek. Thus, moments of terror during which a scream is anticipated yet not delivered in the customary way can be especially jarring: Janet Leigh's many screams in Alfred Hitchcock's infamous shower scene in Psycho (1960) are aurally juxtaposed with the high-pitched shrieks of violin stringsshrieks too loud and too sharp to come from her human voice box-while in an earlier Hitchcock film, The 39 Steps (1935), the scream of a woman discovering a corpse is substituted with the protracted, intensively mechanical whistle of a passing train, effectively transitioning one scene seamlessly into the next. These instances thwart the viewer's expectations of the scream, betraying the filmic promise that wide eyes and a gaping mouth will be accompanied by that shrill vowel of wordless embodiment. In these examples, the horrors of each situation-the disembodied hand of an unseen killer wielding a knife that penetrates Leigh's naked flesh or the sudden discovery of a dead body - are only further exacerbated by the unexpected outcomes Hitchcock creates. In science fiction, few directors experimented or toyed with the scream in innovative and provocative ways others working outside the genre, such as Hitchcock, have done.

When the scream is delivered in a customary way - anticipation followed by visible threat (either onscreen or off-) and the inevitable payoff of a satisfying vocal delivery provided by a beautiful damsel-in-distress - the viewer finds unquestionable visual and aural pleasure to relish from the safety and security of a plush cinema seat. Sci-fi films from the genre's golden age consistently provide these pleasures. And while the damsels and monsters were exchanged 
for even prettier dames and ever more hideous creations throughout the 1950s, the scream remained one of the constant underlying threads that weaved the genre into a cohesive body of films that promised to thrill and delight cinema-goers, from Patricia Neal's shrieking in The Day the Earth Stood Still, to Helena Carter in Invaders from Mars (1953), Faith Domergue in It Came from Beneath the Sea and This Island Earth, and Alix Talton in The Deadly Mantis (1957).

While the screaming woman enjoys frequent appearances in the genre, analysis of the meaning of such vocal releases as hers is oddly overlooked in the critical literature. Given that science fiction is teeming with enough thematic preoccupations unique to the genre to fill copious essays and books, the scream has not been a major focus for critics. Attention to the genre's thinly-veiled allegorical treatment of Cold War anxieties abounds across most scholarship, with more recent studies discussing issues of gender and race in relation to narrative construction that highlight the relevant historical realities of the decade (see, for instance, Cornea, Science Fiction; Adilifu Nama, Black Space; and Noonan, Women Scientists). Within the classic literature on the topic, the scream is at most a sidelong glance waiting to be returned. Sontag's "The Imagination of Disaster" briefly alludes to "a symphony of screams" as part and parcel of the aesthetics of destruction in sci-fi that she so aptly outlines; however, Sontag does not go beyond this mention as her concern lies more with painting the broad thematic brushstrokes of the genre (213). Sobchack's treatment of the sounds of science fiction draws our attention to the voice through the use of alien language, the displacement of human speech onto robots or animals, the proliferation of banal scientific jargon, and the use of language in sci-fi parody, comedy, and satire, but her study does not turn its focus to the scream (Screening Space 146-222). Nevertheless, Sobchack's preoccupation with the voice, stylized dialogue, and 
language use in the genre are useful entry points into considering how other speech acts are implicated within the structure of sci-fi.

Beyond the realm of science fiction criticism, authors interested in other areas of film have commented on the meaning and signification of the female scream. In a much broader study of the voice in cinema, Chion links the voice with death, the almost-dead, and the waiting-to-die: "Particularly in the cinema, the voice enjoys a certain proximity to the soul, the shadow, the double - these immaterial, detachable representations of the body, which survive its death and sometimes even leave it during its life" (47). Similarly, Britta Sjogren argues that the female scream represents "a body's (impending) mutilation, and, subsequently, the character's subjective disappearance from the film text" (78). Chion's interest in the cinematic scream flows from this connection between voice and death, for the scream indicates a moment of uncertainty in the instance when the body is threatened and the character's resulting fate is unclear. In his brief but captivating thoughts on the topic, Chion defines what he terms "the screaming point" as something that generally gushes forth from the mouth of a woman, which by the way does not have to be heard, but which above all must fall at an appointed point, explode at a precise moment, at the crossroads of converging plot lines, at the end of an often convoluted trajectory, but calculated to give this point a maximum impact (76-77).

Chion's screaming point is the central most important moment around which a film is structured, executed with precision and carefully placed within the narrative to rouse audiences from passive viewing and engage them in the sensory experience. In preparing for the ultimate thrill of this moment, Chion writes, nothing is spared: "Twenty-story gorillas are invented, a thousand-foot-tall building is set ablaze, deluges of fireworks, symphony orchestras, the most ingenious and sophisticated details of productions ... nothing is too elaborate or far out if it will 
lead to a successful scream" (77). These thrills and elaborations are mainstays of science fiction. In Earth vs. the Flying Saucers, an alien invasion film that culminates in what Warren praises as "a highly satisfying orgy of destruction" (259), Ray Harryhausen's skilfully-designed flying saucers demolish several famous Washington landmarks - Union Station, the Washington Monument, the Capitol Building, and the Supreme Court Building among them-as panicked onlookers flee in mass exodus, stopping only to sneak glances at the spinning spacecrafts whirring and screeching above them. As suspense builds within the score (by Mischa Bakaleinikof), brief shots cut between the army racing to launch defence missiles and the seemingly invincible intruders who continue to fire at any building in sight. At the height of the battle, an unidentified young blonde woman runs towards us directly into centre frame. With her gaze upwards and offscreen, she screams directly into the camera, producing at once a noise muffled by the deafening sound of the war machines overhead. Upon her face is etched utter helplessness and her scream confirms the worst: chaos has descended and the battle has begun.

Similarly, in War of the Worlds, violence anticipates the release of a satisfyingly shrill scream of the female protagonist during a stand-off between humans and invaders. George Pal's superbly-crafted alien war machines are stealthy, shiny triangular vehicles encased in metal, relentless in their pursuit of destruction and (seemingly) resistant to all forms of attack. Beloved Pastor Collins, reciting verse from the book of Ezekiel in the name of peace, advances toward them and is suddenly ruthlessly vaporized by the heat rays of those treacherous Martian machines. The film cuts to a close-up of the head of the probe as red, yellow, and white light fills the screen. The sound of the blast deafens, and before Collins's unfortunate demise can even resonate with the viewer the next shot cuts to the face of his niece, Sylvia Van Buren (Ann Robinson), bathed in the same menacing blood-red glow of the beam that has been disintegrating 
her relative in front of her eyes. Leith Stevens's music swells and Van Buren's scream pierces the air along the same frequency as the shrill sound of the alien weapons; the ear is assaulted with a cacophony of strings and shrieks. As in Earth vs the Flying Saucers and here, the screaming woman is the payoff to graphic images of violence and destruction. Nothing is held back: national monuments are blasted to rubble, a peace-mongering priest meets his maker, and the acute horror spills out in the scream of women caught up in the wrong place at the wrong time.

\section{Sex, Silence, and the Shriek}

Warren's use of a sexual metaphor-"an orgy of destruction"- to describe the violent imagery in Earth vs, the Flying Saucers is unsurprising, given the longstanding connection between sex and violence in cinematic history. The unquestionable link between phallic symbolism and guns and missiles that penetrate the enemy with forceful impact, leading to overthe-top explosions, bloody corpses, and the display of enemy viscera, need not be drawn out here. What is important is that within science fiction's male-dominated action-centred narratives, the displacement of sexuality onto technology, science, and alien mutants is a common occurrence. Sobchack argues that sexuality—including female sexuality, male and female desire, and biological reproduction-are repressed themes in the genre ("Virginity" 103). Aside from chaste kisses and obligatory romances sex is notably absent, with very few exceptions. Sobchack's psychoanalytic approach, one that has been embraced by many scholars, concludes that sexuality emerges in sci-fi in forms subject to condensation and displacement, as we find within the dreaming state. Thus it is, as Sobchack points out, that when a female character in Invaders from Mars is strapped to a table in a dark underground lair about to have her mind taken over by aliens by virtue of an injection at the nape of her neck, the long tubular mechanical probe 
aiming at her is not merely suggestive of intellectual invasion but also connotes sexual or erotic penetration with underlying implications of rape and sodomy (113). Bonnie Noonan takes a similar stance in her study of giant-insect films of the period, arguing that the sexual characteristics these creatures embody illustratively provoke American cultural fears and anxieties related to the dangers of unrestricted female power and uncontrollable sexuality. Noonan interprets the imagery associated with the giant insects as undeniably sexualized. The tunnels in the Los Angeles underground sewer system of Them! (1954), for example, are likened to "interminable vaginal canals," a "mysterious female space through tubelike culverts with shallow water flowing through them, enacting a reverse entry into a polluted birth canal" (81). Close-ups of the mutant spider in Tarantula "reveal a gaping vaginal maw whose swollen, glistening labia seem to pulsate with pleasure as they devour their victims" (86). Finally, the horror of the enormous creature in The Deadly Mantis stems from "the intertwining of male and female body parts in the same body and the inability to unmistakably decipher them" (95). As Sobchack and Noonan affirm, violent images are without a doubt laden with sexual connotations in science fiction film, filling in for the noticeable lack of sexual interaction between human characters.

Even the 1950 s space ship, epitome of sterility, functionality, and minimalism, can be sexually suggestive. Rocketship X-M is one film among many to feature a notable example of this type of craft, with its long, smooth, metallic shaft that flies through space penetrating the unknown universe, a phallocentric design choice (by Theobold Holsopple) that repeatedly emerges in countless other films (such as Destination Moon, When Worlds Collide, and Proiect Moon Base [1953]) throughout the decade. Asexual male scientists and astronauts transcend earthly desire and the limitations of human flesh and set their sights higher upon an expectant 
universe, vast and expansive and waiting only to be conquered. Women, not quite ready (or permitted) to advance with the modern world, can wait. Accordingly, in a genre marked by its simultaneous sexual nullity and sexual confusion, torn between erotic repression and overtly suggestive imagery, the voice of the screaming women shatters a peculiar and definitive silence, highlights a troubling ambiguity, and exposes those contradictions. Within the context of the repressed erotic symbolism flourishing within the genre, the female scream singles out the body of the woman as the site of vulnerability upon which ghastly horrors are to be enacted.

Brophy goes so far as to classify the generic filmic scream as an "aural cum shot," an ironic description given Sobchack and Noonan's suppositions about sci-fi chastity. Brophy views the trajectory of the plot leading up to a woman who eventually and inevitably screams as mimicking what he sees as the three stages of human sexual dynamics: sensation, arousal, and orgasm (53). For Brophy, the scream is a substitute for a potential but rigorously elided onscreen image, for it "operates as a phoneme for that which cannot or does not want to be shown" (53). Echoing Brophy's claim that the scream acts as a replacement for certain images, Sjogren writes, “A woman's scream, an auditory excess, points, in a general sense, to a violence done the woman's body/image on-screen or off-it comes to stand, like a strange synecdoche, 'for' the woman's body, to which something frightful has been done" (11). Images of graphic sexuality and violence, in Brophy's view, are both feared and desired by the audience, a conflict which ultimately leads to a "crisis in consumption for the cinema" that may be resolved by invoking sound, the invisibility of which can suggest the unwatchable or unknowable (54). In other words, when a filmmaker has exhausted the onscreen limit of blood and brutality, guts and gore (due to either the restrictions of ratings, social strictures, or censorship of violence), the aural realm may be turned to in order to upset or startle the senses in ways that an explicit image cannot not. At 
the point of that scream, when aural perception relinquishes control from the dominance of image perception, the imagination takes over. It is up to the viewer to fill in the blanks of what could not be shown which, is many ways, is far worse than what any director could ever possibly show.

This is certainly the case in sci-fi films, which rarely show the resulting gore caused by alien missiles or radioactive beasts. In Earth vs. the Flying Saucers we do not see the blonde female screamer bruised and bloody under a pile of debris at the Supreme Court Building. Her location during the invasion suggests that such an ending - or worse - does lie in store for her but the film remains open as to whether she escapes to safety. Instead of moving, she screams, and viewers can merely speculate what will happen to her the moment the film jumps to a location across the city to check up on the military. Likewise, in War of the Worlds, we are not bombarded with the sight of Pastor Collins's smouldering corpse in the afterglow of the heat ray. The film does not have to include this image to permit the viewer to make that leap of logic as, again, the scream that follows suggests as much. Van Buren's scream, after all, is the substitution for his body, his viscera, his ashes. The red glow of the heat ray cast over her face is his blood (and hers, too, given their familial connection), the visual excess spilling into the frame from offscreen. At least in the 1950s, given Production Code limitations on violence in film, it was much more acceptable (not to mention visually pleasing) to show a pretty young woman's reaction instead of the horrors confronting her. After these women scream, we know we have just been shown the worst, and we can finally release that held-in breath and relax (for now, at least, until the next visual fright). The scream provides momentary closure in such instances, offering resolution in the way an image cannot, for if it is she who sees the horror, we do not have to. 


\section{Giving Voice to the Unknown}

If the scream stands in for what cannot be shown, this is where its function as a statement of anything conclusive ends. The scream is ambiguous. It is confusion sung hysterically as an atonal staccato note. Crucially, while a scream is a response to a problem, it does not provide solutions. The screams of women do not stop alien warfare, scare off mutated insects, or prevent certain doom from running its due course. If anything, the scream only draws attention to the screamer, usually making her situation worse. As Hrvatin gravely tell us, "The horror of the scream is that if we want somebody to respond we must not scream" for while the scream is indeed "an act of communication," it ultimately remains incomprehensible (86). Chion takes the unintelligibility of the scream even further:

The screaming point is a point of the unthinkable inside the thought, of the indeterminate inside the spoken, of unrepresentability inside representation. It occupies a point in time, but has no duration within. It suspends the time of its possible duration; it's a rip in the fabric of time. This scream embodies a fantasy of the auditory absolute, it is seen to saturate the soundtrack and deafen the listener. It might even be unheard by the screamer (77).

The scream, in Chion's view, is "the absolute in terror and pleasure," embodying "an absolute, outside of language, time, the conscious subject" (78). Brophy similarly argues that the scream is a desperate "return to the primal," one that "short circuits all linguistic operation" (55). As these scholars would agree, in the same way that the visual aspects of the scream-that is, the close-up of a female face in hysterics - stands in for what cannot be shown, so do the aural aspects of the scream stand in for what cannot be said. Effectively, the scream proves that there exists a realm in which knowledge is simply not possible. 
As it is seen in film, the scream tends to circumvent the rational thinking of the screamer and to strike as reflex to the unexpected. Sometimes this can be played upon to great effect in order to startle an audience into assuming the presence of danger when it does not actually exist. It Came from Outer Space draws on this effect to build tension and suspense in the moments leading up to alien-human contact. Astronomer John Putnam (Richard Carlson) and his fiancée, Ellen Fields (Barbara Rush), are driving home after investigating the site of a meteor crash. Along the nocturnal highway, the moans of a Theremin signal the presence of something otherworldly. In the dark, with nerves running high, Putnam shines his headlight on the ground - a shot framed by darkness with only a small circle of light in the middle of the frameand we see mostly shrubs in darkness and shadows. When the light is quickly drawn upwards, Fields screams offscreen at the sudden revelation of what was, moments ago, shrouded in darkness — only a tree. Putnam consoles her, "It's just a Joshua Tree." In a second instance later in the film, Fields answers the doorbell at her home. She opens the door and finds an alien in a shiny metallic space suit standing expectantly. The shot returns to Fields's face in a close-up, and she shrieks loudly with force. Again, another false alarm, for it is only a neighbourhood boy in a costume. These false alarm screams each punctuate the film with a sharp jolt; when Fields yelps, we expect (and even wish for) something dreadful to jump out from behind the tree or over her doorstep perhaps to attack her, but nothing happens of that nature. Fields is on edge through the entire film, as are we, anticipating the inevitable threat that the film's title promises. Whatever "lt" is, it is not from this planet but from outer space, and is to be feared, dreaded, and avoided (at least until it can be explained or rationalized with science). Director Jack Arnold crafts this sense of expectation and worry by steering the audience into a few dead ends during the film. As 
we await the inevitable climactic horror with a growing sense of apprehensive expectancy, it is Fields who screams for us.

Although Fields cannot articulate her uneasiness, she somehow senses that something is wrong. Her misguided screams are instinctual and unexplainable. When language is immediately unavailable, the scream is the only possible recourse she has to express that which cannot be expressed. In Hrvatin's view, “The scream appears where speech fails, or where we are not allowed to speak. But the scream is not an act which would convey something that language cannot; rather it conveys directly that language cannot convey anything (any more)" (86). The scream, as it is voiced by Fields (and by Van Buren and the nameless blonde), is the only appropriate reaction to the film's terrifying provocations. The scream is absolutely certain, precisely voiced through its soprano articulation and monosyllabic embellishments.

As we have seen, at the moment of horror when the scream is provoked, such a speechless utterance is often the only response capable of being voiced by women in distress, a sound-image event which stands in for something even more horrific than the shriek itself. Within science fiction, the wordlessness of the female scream exists in opposition to the longwinded monologues of all-knowing male scientists who seemingly have answers for everything. Yet, ultimately, the sound of the woman screaming and the jargon-filled banter of the male scientist function similarly: given the circumstances, both are equally the most appropriate and logical responses to the stimuli presented to them. Heroines who scream in sci-fi confront what lies beyond the limits of knowledge: the fantastic, the extraordinary, and the uncanny as well as the repulsive, the horrendous, and the absolutely unbelievable. 


\section{Chapter Three: The Screaming Woman}

Within the chorus of screams bursting forth from the mouths of female scientists, secretaries, and sweethearts in the science fiction film, three intriguing instances stand out. These scenes mark the meeting of women and the unknown, when language suddenly fails and muteness prevails, when she looks directly into the eyes of a being from another world and a brief exchange- sweet and harmfully innocent or violent or perhaps something in between?occurs just before she shrieks. Consider the following trio of screams:

Early on in Edgar Ulmer's 1951 film, The Man from Planet X, Enid Elliot's (Margaret Field) car stalls on the evening drive home and she finds herself alone on the road. Thick blankets of fog cover the Scottish grasslands around her and a strange light flickers in the distance. Curiously, she approaches. As she draws nearer, we hear a loud humming sound rhythmically pulsating in time with the flickering light as it glows from the windows of an oddlyshaped bulb jutting out of the sand. Pizzicato strings mimic her tentative footsteps towards this strange spaceship. Her fingers absent-mindedly touch the smooth exterior of the bulb as she moves in to get a closer look. As she feels her way up the side of the ship in the darkness and fog she discovers a window. Movement from within the ship reveals what looks to be a little manhairless, with pointed features, and clad in a transparent helmet affixed to numerous coils of wires - who meets her gaze on the opposite side of the glass just as she peers in. Their faces nearly touch — save for that protective layer of windowpane — and Elliot's hands rush to cover her mouth as she suddenly screams.

The second moment occurs towards the end of Robert Wise's The Day the Earth Stood Still. Helen Benson (Patricia Neal) rushes to find the giant robot Gort at the site of Klaatu's (Michael Rennie) spacecraft in order to relay an important message, drums pounding as she 
carefully approaches. Gort stands ominously ahead of her, partially masked by the night shadows and partially bathed in an eerily pulsing white glow. He stands stoically without moving, the contours of his metal-plated body impenetrable to even the most advanced military weaponry. Shots of Gort emphasize his stature and strength, framing his body against the sleek curves of the docked space craft behind him, closing in on his upper body and head, or angling downward to dwarf those who dare approach him. His head is covered entirely with a helmet-his face is never revealed, or perhaps he has no face at all—with a visor in place of eyes that lifts only upon threat of attack to emit a ray of light that disintegrates anything or anyone in its path. Helen gingerly approaches, absolutely diminutive in comparison. Bernard Herrmann's score further heightens the tension of the scene: lengthy notes of a wavering Theremin are heard as electric strings (violin, cello, and bass, as uniquely and unusually arranged by Herrmann) provide a minor chord in support of the rhythmic beats of the bass drum. In this moment, the sounds of the drum are the heart beats realized, irregular and unpredictable, slow and steady. As Gort starts to move toward Benson, she backs up only to find herself trapped against a wall. Gort's shadow looms over her and she disappears from view into the darkness cast by his frame. His shadow shifts slightly and her face is revealed just as she screams before collapsing onto the ground in sheer terror.

Finally, consider this scene at the climactic height of Joseph Newman's This Island Earth, in which we find Dr. Cal Meacham (Rex Reason), Dr. Ruth Adams (Faith Domergue), and Exeter (Jeff Morrow) now departing the war-torn planet of Metaluna in a rocket ship bound for Earth. Unbeknownst to the crew, a Metalunan mutant also boards silently behind them; trouble is afoot! The mutant is hideous, with its shell-like upper body encasing, its large protruding beady eyes and bulbous, vein-covered brain, and razor sharp red claws attached to extended, flopping 
arms. Exeter, Ruth, and Meacham enter a trio of Converter Tubes, cylindrical glass chambers that use magnetic energy to enable the body to inhabit different atmospheric environments and, in the process, induce temporary paralysis. The three enter a state of semi-consciousness, eyes closed, heads heavy, as wisps of smoke fill up the lower half of each chamber. In the midst of this process, the door to the cabin opens and a shadow of the mutant's claws appear on the wall. Adams, her conversion nearly complete, raises her head and flutters her eyes open to see the mutant enter the cabin just as all three are trapped within the Tubes, unable to move. The monster menacingly stumbles towards Adams, who belts out a loud shriek of terror from inside her chamber.

At the heart of each these three encounters exists a scream that cuts across language, filling the silence shared between woman and the unknown. Whether in response to a robot, mutant, or humanoid alien, such as this triad of screams suggests, female fear within $1950 \mathrm{~s}$ science fiction is typically directly towards something unspeakably horrific and yet undeniably masculine, embedded deeply as it is within the representation of the alien Other.

\section{Screaming, Muteness, and Desire}

The screaming woman in each of the above instances briefly disrupts what Sobchack describes as "the banality, the laconic and inexpressive verbal shorthand and jargon, the scientific pomposity" that characterizes the stiff and dull verbosity of science fiction dialogue (Screening Space 151). The use of elevated and hyperbolic language in science fiction exists alongside the scream as among its most notable conventions. Few sci-fi films lack lengthy scenes that serve to lecture audiences on scientific principles: how to launch a rocket ship, how the solar system is organized, or how the laws of physics function in outer space. The scream provides a brief pause from the intellectual chattiness, language that Sobchack views as necessary to 
counterbalance the fear induced by unsettling and incomprehensible images (151). Screaming women upset the rationality of purposefully scientific language by articulating the fear that exists on the other end of the linguistic spectrum, fear which cannot find its way into words. When the woman encounters the little man, the giant robot, or the wounded mutant, she finds herself unexpectedly caught up in an unsettling silence. Delicately plucked cellos, arrhythmic percussion, and the moan of a Theremin are our only aural accompaniments up until this moment, musical replications of her body's fearful response that fill that otherwise silent void. Language is no longer relevant or even useful as she lapses in shocked speechlessness in the moment before she screams. Her alien pursuer is similarly afflicted, trapped inside a glowing bulb, lacking the mouth associated with speech, or finding himself otherwise mute. Within this silence, a brief yet compelling exchange occurs between woman and Other: a touch, a glance, a curiosity that quickly devolves into terror.

Perhaps because of Gort's inability to speak in The Day the Earth Stood Still-does he even possess a mouth, vocal chords, or larynx, hidden behind his helmet?, one will never know-Benson does not attempt to communicate with him using English words, and her scream is accompanied only by the repetition of Klaatu's mysterious alien instructional phrase. Benson's scream is also her brief moment of fear-driven irrationality before she regains her composure. Gort's jerky movements toward her are suddenly paused as the visor lifts, the tell-tale fatal beam of light glimmering just behind it. Benson cowers on the ground but gains a sudden strength as she turns her gaze upward toward him and declares what remains one of the most famous lines in science fiction cinema: "Gort! Klaatu barada nikto!" When she has uttered that short phrase, Gort's visor closes. As he approaches her, his body moves out of sight into the shadows. He emerges a second later with Benson now in his arms, her hand upon on his chest and her eyes 
fixed firmly and cautiously upon him. Her legs and black high-heels are the first to come into view now as Gort carries her up into the ship-almost as if crossing over the marital threshold.

In this moment, her facial expression reveals her fear of the towering robot's brute force and yet her fingers glide over and caress his metallic frame in an instance of curiosity combined with forced acquiescence to his strength and power, her legs dangling over his arms and framed against the ship by the soft glow of the evening's moonlight. This encounter between Benson and Gort is brief but highly suggestive, intimating that the calm, soothing sound of a female voice is enough to calm this savage robotic beast who only moments earlier had displayed his capacity to kill by disintegrating a group of soldiers with a swift blast from his visor. Benson's soft and curvy womanly figure, as clad in a dark and billowy A-line dress that reveals shapely legs and heels, stands in stark contrast to Gort's rigid limbs and shiny, steel surfaces. Their ascent into the ship signals the meeting of opposing textures and tactile sensations of the feminine and the robotic that mark otherworldly difference and are harmonized in the image onscreen. The linguistic barrier between them is supplanted by their physical contact as Gort carries her from the shadowy darkness of the field to the brightly lit interior of Klaatu's ship. Here, she is safe and may rest easy away from piercing police sirens and the attack of military firing. In Gort's arms, Benson experiences the alien become familiar. Her scream is therefore a mere first impression, eventually changing as her fear transforms into curiosity and, finally, trust.

As it is visible to both Elliot and the viewer, the spacecraft jutting out from the sand in The Man from Planet X resembles a face: its jaunty angle suggests a playful invitation to "come hither" that compliments the hypnotic pulsing glow of the light spilling from its two windows. Elliot draws closer to these wide-open blinking eyes as if pulled by some unknown magnetic force. She approaches purposefully—cautiously, maybe, but also intently--toward the ship; she 
is, after all, the daughter of a scientist who knows that herein lies a problem to be solved through observation and thorough investigation. We watch her as her own eyes take in this curiously attractive sight, for she is not yet fearful and is genuinely interested in her discovery. Indeed, the ship looks like nothing other than a gigantic spinning top, an innocent children's toy for her to play with, momentarily suspended in the swirling night fog and ready for a twirl. Her fingers caress the side of the ship, exploratory yet gentle: perhaps there is a door to get in? And then, without warning, a man appears! Their faces nearly meet on opposite sides of this third eye of a window-in a kiss? Her trance is forcefully broken as reality hits. The blinking eyes now seem menacing, even taunting, as she shrieks and races back to the road. And so it appears that the two of them, this odd little creature from some unknown, unnamed planet (" $\mathrm{X}$ " is both everywhere and nowhere, it would seem, in these films) and this young woman out alone at night engage in a brief encounter. She wants in and he wants out, and they briefly dance in and around the ship before a final step brings them together. Her desire to learn more about this peculiar vehicle draws her to him, but the revelation of his face scares her away. In the silence that exists between them as they stare at one another through the glass window, the gaze is met and broken with her wordless scream.

Non-human creatures in science fiction, if not as talky as their human counterparts, are often mute. This lack of linguistic ability renders their intentions unclear or ambiguous. It may just be a childlike curiosity that draws the alien or mutant towards what he sees as an unfamiliar Earth woman clad in strange human clothing, or it may be an automatic response of a robot to destroy anything that threatens to come too close to his spacecraft. Alien muteness heightens the suspense: if only he could talk, the woman (and the viewer) would know his purpose. A silent cacophony of desires accompanies these encounters: the multiplication of suppositions and 
questions, the need for answers and for resolution that leads to safety and security, and the hunger for communication beyond a mere furtive glance. Without language, the meeting of woman and alien relies on the senses to provide the answers: is this a fiiend or a foe?

In This Island Earth, Adams not only struggles to grasp for understanding in the face of silent danger, she also struggles to move, trapped within her chamber. As the mutant staggers nearer, Adams's vulnerability is further exacerbated by the restricted ability of her male colleagues who look on in horror, paralyzed and unable to help. Her head shakes back and forth as if to wrench herself free and her screams continue, piercing the air with shrill terror. Adams is the first to finish with the conversion process but as the glass chamber rises to release her, her freedom is in vain: the mutant's claws close in on her! Without weapon and alone with the Metalunan, her body is defenseless as the mutant catches her in its grasp after a brief yet heated chase around the cabin. He grabs her from behind and clutches her in what can only be called a tight embrace, holding her up in the crooks of his clbows and lifting her off the ground while her legs scissor furiously in midair. Is this a predatory grip or the innocent curiosity of a fatally wounded being whose death wish is to feel the warm body of another against his chest? The mute mutant reveals nothing, not even a telltale roar to indicate dominance or the thrill of the hunt. The scene draws its suspense precisely from this ambiguity: what will the mutant do when "he"- as referred to by both Meacham and Exeter—catches her? What horrors will Exeter and Meacham be forced to witness, trapped within the confines of their glass chambers? The answer lies just out of reach for all, perhaps even for the mutant himself as he stumbles somewhat aimlessly towards Adams with claws flapping about madly. Of course, this narrative uncertainty is the cornerstone of the pleasure of this scene, with Adams's scream a satisfying exclamation mark to the whirlwind of emotions that precede it. It is worth noting that Adams's screams are 
many throughout this sequence - six in total $—$ a combination of synchronous and asynchronous staccato vocalizations that accompany the fear etched upon her face. Her screams are present in stark contrast to the mutant's lack of a voice, effectively shattering the silence. Adams manages to break free from his grip following a brief struggle, and almost immediately the alien collapses onto the floor from the pressure inside the cabin, disintegrating first into a skeletal frame and then into a hazy yellow smoke. After the mutant disappears, Adams is reduced to silence; her screams die with him and we cannot help but wonder whether it was his voice she was articulating all along.

In her discussion of the aural style of Alfred Hitchcock, Elisabeth Weis argues that "At the furthest end of the continuum from silence there is usually a scream, an outburst of pure, noncognitive feeling. If silence is the common denominator of most sorts of control, the scream is the common denominator of most extreme emotion" (161). In science fiction, the scream indicates such a loss of control by way of a female character acquiescing to an overwhelming sense of fear which, in these examples, is provoked by a chance meeting with an alien being. Silence, while a measure of control and composure when exhibited by human characters (who are, most often, male, a point to which we will return in Chapter Four) instead indicates the presence of something entirely uncontrollable when associated with nonhuman creatures. What we have seen, as contained within these three vignettes, is the moment when fear, desire, and curiosity coalesce and the woman screams. The woman expresses her terror just as the creature from another world moves in to get a closer look, wanting or desiring something from her that, without the assistance of language, she will never quite find out. The genre's emphasis on banal jargon, talky characters, and scientific exposition further exacerbates these moments of muteness in which the calm, cool, and collected rationality of science ultimately dissipates into chaos and 
confusion. Within this confusion lies the silent alien desire for a kiss, an embrace, or even just a returned gaze. In each of these three cases, the displacement of eroticism onto alien beings lends itself to female characters shirking in fear, unaware of the intentions or desires of their interplanetary counterparts.

\section{The Curious Gaze, the Shared Glance, and the Scream}

Women often bear the burden of being the first (and sometimes only) humans to make physical contact with - that is, a combination of seeing, hearing, touching, or being touched bybeings from other worlds in 1950 s sci-fi. On one hand, these moments are revelatory, first forays into interplanetary communication while, on the other, such moments usually imply some type of impending threat or violation of the female body - sexual or otherwise—as suggested by that sudden, shrill scream one comes to expect (and delightfully relish) from such utterly terrifying encounters. The scream that occurs when the woman and alien meet accompanies a momentary look of horror as she is forcefully confronted with something so un-human, so frightfully unrecognizable, so outside the realm of her knowledge that her only recourse is to lapse into instinctual fight-or-flight mode. This scream is usually paired with averted eyes, hands rushing to cover the face, or a quick turn to flee in the opposite direction, a phenomenon explained by Linda Williams in her analysis of the female gaze in the classic horror film. In her view, when faced with frightening images, female characters onscreen often fail to or refuse to look, instead "cover[ing] their eyes or hid[ing] behind the shoulders of their dates" ("When the Woman Looks" 15). Expanding on Laura Mulvey's influential work on the cinematic gaze, Williams attributes woman's refusal to look with her absence of desire or lack of interest to take part in the pleasure of seeing because "she exists only to be looked at" (15). Conversely, Williams argues, a curious or inquisitive female gaze is one that cannot go unpunished, a pattern best reflected in 
the horror genre wherein the look exchanged between the monster and the woman precedes her necessary and inevitable victimization. This curious gaze in horror, however, is not purely masochistic or solely exemplary of female disenfranchisement. Rather, the horror-monster film is "a rare example of a genre that permits the expression of women's sexual potency and desire," one that "associates this desire with the autonomous act of looking" (32). In short, the curious gaze in the horror film allows the woman a brief moment of agency, autonomy, and desire while also foreshadowing her inevitable doom.

While horror and science fiction film share many commonalities, themes, and visual and narrative tactics, what constitutes the central terror or monstrosity in each genre differs greatly. For Barbara Creed, the horror film "abounds in images of abjection" including human bodily wastes, the crossing of borders that challenge the nature of being human (good and evil, human and inhuman, man and beast), and the construction of the maternal as the monstrous-feminine (253-254). Horror films, Creed argues, are concerned with images of the monstrous as they are symbolically linked to the archaic mother as either a negative force or as death, images that place the viewer into crisis until the monster is successfully named and destroyed (261-62). In science fiction-horror hybrid films (or "creature-features," as they are now known), this is often the case with monstrous beings that originate on Earth as a result of science gone awry, in which the representation of copulation and procreation are reworked by patriarchal ideology to "deny the 'difference' of women in her cinematic representation" (259). The giant ants in Them! and the oversized arachnids in The Incredible Shrinking Man (1957) and Tarantula are notable examples of Creed's monstrous-feminine, monsters which are portrayed horrifically in terms of symbolic imagery of menstruation, childbirth, and female genitalia (for Creed, the ultimate example of the monstrous-feminine may be seen in Alien [1979]). Still, a large body of science fiction does not 
concern itself with that which originates on Earth as a result of human interference with nature; instead, many films take place on other planets or deal with alien creatures who somehow make their way to Earth. As Sobchack has noted, the science fiction genre erases biological sexual and reproductive functions from its narratives, displacing these themes onto mutant life forms and technological activity ("Virginity" 105). Given this noted absence of sexuality and human reproductive functions in the non-Earthly focused science fiction film, Creed's monstrousfeminine disappears, irrelevant in the depths of outer space. Broadly speaking, alien life forms in sci-fi do are slick and streamlined (either in their natural form or with the assistance of flying saucers, rocket ships, advanced technological gadgetry, and space suits), noticeably lacking the reproductive and otherwise bodily excesses that characterize Creed's monstrosities, abjections which are firmly rooted in the human, specifically the feminine. Science fiction instead opts for monstrosities which are asexual, inhuman, and transcend the necessity of human bodily borders in the first place. In doing so, such monstrosities are unequivocally and undeniably masculinized, symbolic of the body which does not leak, seep, weep, or gush forth with abject (feminine) wastes. In the externally-focused, otherworldly science fiction film, the feminine is not the source of monstrosity. Rather, it is entirely the absence of femininity that underpins the genre.

Unsurprisingly, alien invaders from other worlds are usually specifically gendered as male, either through narrative - as in those cases when human characters refer to such aliens as "him" rather than "it"-_or through visual signifiers such as body shape. An easy inference of maleness is not unfounded given the fact that said creatures are usually-and, given the costume design, quite obviously -portrayed and voiced by male actors. Imposing human understandings of the gender binary onto aliens from other planets is a curious yet common practice within science fiction; after all, the assumption that a dichotomous gender system exists throughout the 
vast expanses of the universe is a rather naïve humanistic approach on part of scientists and astronauts (not to mention screenwriters). Take, for instance, such films as The Man from Planet $\underline{X}$ or The Thing From Another World. In both of these films, an alien from another world makes contact with humans and in each case the alien looks like a man, is shaped and built like a man, and facially emotes like a man, but is most certainly not human. Still, we are treated to close-up shots of the eponymous man from Planet X, while the Thing (James Amess) is referred to as "him" or "he" even after he is decided to be no more than an "intellectual carrot." Moreover, humanoid aliens are human actors with stilted, overly-articulated speech patterns and unusual wardrobes (such as Klaatu in The Day the Earth Stood Still) and even more radically bizarre hairstyles atop drastically raised hairlines (as with Exeter in This Island Earth). During the course of the film, we can momentarily suspend disbelief in their otherworldly nationality but even as the film's charms allow us to lose ourselves in its delights, all along we know that we are watching men. Not aliens, but men. For the screaming woman, this distinction is crucial.

Williams argues that the look of terror directed towards the monster in the classic horror film differs for men and women. The male look of horror, she writes, "expresses conventional fear at that which differs from itself" while the female look "shares the male fear of the monster's freakishness, but also recognizes the sense in which this freakishness is similar to her own difference" ("When the Woman Looks" 20-21). Williams suggests a willingness on behalf of the female character to recognize her own monstrosity in a kind of "sympathetic identification" (21). This moment of female-monster identification occurs when the woman realizes that both she and the monster exist within the patriarchal system of looking as mere objects or spectacles to be gazed upon. 
In This Island Earth, the culminating interaction between the mutant and Adams is literally a spectacle for male viewing, both Exeter and Meacham being paralyzed within their Conversion Tubes and able only to watch helplessly. As the mutant stumbles near, Adams's body is rigid, her eyes alone capable of movement. She peers out of the glass, with eyes wide and expectant, at what awaits her outside her chamber while the conversion process finishes. The interaction between Adams and her alien pursuer in this brief moment occurs entirely via the exchange of the gaze, one both curious and fearful. Their eyes meet several times in a shared gaze, bodies separated only by a thin layer of glass and smoke. In Williams's view, we can read this scene as enforcing a system of identification in which man exists apart from woman and alien, the latter two the embodiment of difference from masculinity. From this perspective, Adams may be seen as running away from her own inner monster, her own sexual desires, and her own difference as marked by the patriarchal system of looking as she staggers around the cabin in an effort to save herself from the mutant's grip. The scream could be seen as the moment when Adams recognizes her own monstrosity. Still, in science fiction, this identification is not as clear cut as Williams's theoretization implies. Instead, the unequivocal maleness of creatures from outer space and avoidance of specifically abject constructions of horrific images facilitate the woman's disidentification from the object of her scream. The woman of science fiction may scream at some sort of monster-an alien, a mutant, a robot-but her scream is not directed toward herself in a kind of female-monster affinity. The monstrous-feminine does not find its way into the chrome or metallic fixtures of rocket ships, space suits, or robotics. She screams at something else, something not quite human, something not quite male, but perhaps something that lies between these two. 
Accordingly, Williams's argument may be inverted for the science fiction film. The screaming woman confronts a distorted version of the male characters in the film and her shrieks are a response to the firmly drawn lines of sexual difference. Here, the mutant, with its awkward embrace of Adams in the crooks of his flopping elbows, is none other than Meacham's extraterrestrial doppelganger. Meacham and the mutant share their desire for this female scientist, who spurns each of their advances at some point during the film (in the beginning of the film, Meacham is rejected by Adams in his attempts to rekindle his former romance with her). Continuing on this theme, Gort, in all of his stoic silence, is an inversion of Tom Stevens (Hugh Marlowe), Benson's self-interested boyfriend who plays Judas to Klaatu's messianic messenger when he turns him in to the authorities. Gort's muteness stands in contrast to Stevens's outspoken arrogance and Gort's tender care of Benson in the safety of the ship is the affection Stevens is not prepared, or able, to give her in all of his selfishness. Thus, contrary to Williams's view, the woman described here screarns at that which is different from her-at a being who desires her, in some form or another, a being alien yet undeniably male.

The horror monster, as Williams sees it, operates as a mirror that "offers a distorted reflection of [woman's] own image" ("When the Woman Looks" 22). In science fiction, however, there is no reflected feminine monstrosity, only the singular image of the alien in all of "his" difference. Returning finally to The Man from Planet X, it is the window pane of the little man's ship that separates his face from Elliot's. Outside it is quite dark, hence her hands wandering over the side of the craft to find the window in the first place, for she can barely see in front of herself. Importantly, Enid will not see her reflection when she peers inside. The darkness outside will allow to her see with absolute clarity the creature inside the ship, brightly lit from inside. This, of course, is reason enough for a good scream. She expects an abandoned vehicle, 
not unlike her own stalled up the road, and in this context the alien being startles her into an involuntary reaction when she realizes she is not actually alone. It is the little man himself, however, trapped as he is within that docked illuminated bulb, who will see something even stranger: the light from the ship will obstruct his view of outside and turn the window into a darkened mirror. He will see a distorted interior reflection of himself in the window as he peers out just as he will barely see the outline of a figure standing right in front of him, obscured by the light from within the ship. Quite literally, then, William's articulation of the woman-monster relationship in horror as one of reflection is reversed in science fiction: Elliot sees something extraordinary and astonishing and different through the window. The little man, in contrast, sees only himself as reflected in her image. In fact, it is the alien who sees a distorted reflection of himself in the mirror, an image of his difference from the humans who people the foreign world he has just landed upon. Elliot will later refer to the man in the ship as "A ghastly caricature, like something distorted by pressure. I can't think how else to describe it. A horrible grotesque imitation of face looking right in my eyes." Of course, what she is really describing is "A horrible grotesque imitation of a man's face."

As this trio of shrieks has shown, the woman screams to cut through the brief yet critical silence in the otherwise wordy 1950 s science fiction film. She reacts instinctually towards a distorted reflection of a male who desires her in some intensely yet uncertain way, desires which are initially feared or met with disgust. He is an alien/man, after all, positively terrifying to a woman alone, without weapon, without language, without understanding. She screams at what cannot be said, what cannot be seen, and what the film will not permit us to see in this fleeting instance: the true meeting of the feminine and the alien/male that occurs just beyond the edge of the frame. The scream injects the female voice into the male-dominated narrative, although these 
moments conform to a vision of gender that favours female passivity in the face of danger. Despite the best efforts of science, technology, and modernity to tame her, she is a still a woman: naturally she must scream, of course she should scream, and predictably she will scream. Emotional irrationality in these cases is displaced onto the female body, a necessary outlet from the rest of the film's controlled and conservative masculine posturing. In some ways, the woman's place in the science fiction film may be seen as standing in for male fear when male fear cannot or will not be shown. And so, again and again, she screams. 


\section{Chapter Four: The Screaming Man}

\section{Gendered Embodiment of Fear, Screaming, and Bodily Excess}

Metaphorically, the cinematic convention of the scream finds its expression in the "mouths of babes" as those who express their fear by screaming are usually beautiful and buxom women, lady scientists-turned-damsels-in-distress who momentarily lapse into unintelligible bouts of shrieking. Linda Williams argues that films which prominently feature such bodily excesses - the shudder or scream in the horror film, the cries of pleasure in pornography, or the sobs of anguish in melodrama - belong to what she refers to as the "body genres," or those films in which we find moments of spectacle wherein is prominently displayed "a body caught in the grip of intense sensation of emotion" ("Film Bodies" 4). These moments feature the body "beside itself" which, in the horror film, manifests in expressions of fear or terror in the "uncontrollable convulsion or spasm" of the scream (4). Williams goes on to argue that in these body genres, "the bodies of women figured on the screen have functioned traditionally as the primary embodiments of pleasure, fear, and pain" (4). The victimized woman in the horror film is as much of a spectacle as the monster that terrorizes her, the display of her fear nothing more than "unseemly" and "gratuitous" (5). Williams's theoretical approach works well for the classic horror film; however, as we have already seen, her arguments do not entirely explain some important conventions of science fiction. For example, while it is certainly true that the very embodiments of fear Williams discusses are more often than not centered on female characters in science fiction film, it is also true that male characters are equally menaced by the giant insects, mutants, robots, and aliens populating the remote desert towns, military bases, and rocket ships of the genre. The terrifying evils that inhabit the world of sci-fi know no gender distinction when it comes to clearing a pathway to destruction; indeed, both men and women fall victim to heat 
rays, missile attacks, mind-control, venom-filled stingers, and other unthinkable horrors. And so it also true that both women and men do their share of screaming.

Williams crucially recognizes the gendered dynamics pertaining to the embodiment of fear in horror, but the limited scope of her argument does not account for how to take up male bodily excesses in science fiction. The figuration of the male body, as it appears in genres designed to appear principally to men, is left out of her discussion. While science fiction is perhaps not strictly classifiable as a "body genre" as Williams would have it—the genre shares too much in common with classical Hollywood narrative cinema, characterized by "actioncentred, goal-oriented linear narratives driven by the desire of a single protagonist, involving one or two lines of action, and leading to definitive closure" (3) - its overlap with horror (the "excessive" genre par excellence) permits a reading of certain films as containing certain "excessive" elements. The screaming man is one such example of how the bodily excesses of Williams's "body genres" seep into hybrid genres, suggesting further implications for how horrific elements in film reflect and reinforce understandings of sexual difference, emotion, and gendered subjectivity.

Given the relatively conservative leanings of science fiction during the conformist decade of the 1950s, the representation of male fear is a complex undertaking which contradicts the genre's pervasive assumptions regarding masculine rationality and stoicism. Fear is substantiated in the genre (and certainly in other types of film, as Williams would attest) as a strictly feminine phenomenon, but male fear is not absent. As we will soon see, however, representations of male fear in science fiction conform to certain unspoken rules: first, male heroes must never scream or otherwise exhibit signs of panic under frightening circumstances; secondly, if male fear must be shown in the form of a scream, such characters must be gruesomely killed shortly thereafter; and 
lastly, when in doubt, male fear must be displaced onto the female body. Such displacement is, after all, what she is there for.

\section{The Scream that Never Was}

Chion argues that while a woman's scream gives expression to "an absolute, outside of language, time, the conscious subject," a man's scream does not (78). Rather, Chion views the male scream as an expression of masculine power, territorial marking, or the phallic exhibition of virility. As evidenced by the English language, he writes, men do not scream at all. Instead, they shout. While a man's shout is structuring, centrifugal, and defines territory, the scream of a woman "is where speech is suddenly extinct, a black hole, the exit of being" (79). For Chion, the female scream "is rather more like the shout of a human subject of language in the face of death" (78). Chion recognizes that the gendered nature of the scream is also partly due to the gendered nature of filmmaking. In a male-directed film, he writes, "man is but the organizer of the spectacle, the producer of this extravaganza" (79). As Chion sees it, the male shout is powerful and outwardly directed while the female scream is fearful and inwardly directed. Chion is not the only scholar to make this gendered distinction. Sjogren firmly asserts that "In the cinema, the woman screams. This moment, full of terror, unseeing and unseen horrors, is reserved for a female voice, a voice that seems to have reached some sort of apogee. . . It is difficult, in fact, to remember any film in which a man screams" (78). Sjogren maintains that, in classical Hollywood, the male scream is infrequent, for "A certain form of crisis indeed seems 'best' expressed or represented by the female voice raised by an inarticulate cry" (78). The scream, as it would seem to Chion and Sjogren, is a gendered phenomenon, one clearly marked as feminine. While this kind of theorization reflects a binary approach to gendered embodiment and subjectivity that is not entirely unproblematic, it nevertheless aptly describes the gender 
dichotomy present during the 1950 s, which tended to equate femininity with frailty, weakness, and dependence, and masculinity with strength, assertiveness, and objectivity.

For the most part, 1950s science fiction film adheres to this gendered order. Many of scifi's great screams are uttered by women under duress, followed by the comfort of rugged and protective male heroes who swoop in to soothe their woes. In the context of a genre which (during this era, at least) tends to conflate femininity with emotion and masculinity with rationality, Chion and Sjogren's claims are not unfounded. Social historian Elaine May argues that experts of the decade encouraged women to "embrace domesticity in service to the nation," and enforced ideological connections between sexual containment, early marriage, traditional gender roles, and nationalism (102). Men were also expected to hold up their end of the bargain, and not only as breadwinners. May writes, "Foreign policy itself rested on well-articulated assumptions about masculine power-a power drawn from sexual potency as well as the moral strength to resist temptation" (98). As a direct reflection of the Cold War-era cultural rhetoric May outlines, leading men in science fiction remain calm and collected in the face of danger and do not let their emotions overtake the head-strong stoicism necessary for survival in catastrophic conditions. The first rule of the male scream in sci-fi, then, insists that those who lose their composure must never be heroes.

In Jack Arnold's It Came from Outer Space we are treated to an example of such an unabashedly headstrong male hero who inadvertently finds himself in contact with a group of mysterious aliens hiding in a desert mine. When John Putnam (Richard Carlson) finally convinces the reluctant alien leader to present himself "as you really are"-an alien who, moments ago, had been pleading with Putnam to let him communicate from the shadowy darkness because of his hideous appearance — we are treated to a rare moment in which a male 
hero is forced to confront something so repulsive and unsightly that a scream seems the only fitting response; in fact, he nearly does emit one. As the monster hobbles out of his dim and gloomy confines we catch a brief glimpse: he is towering (perhaps seven or eight feet tall although, interestingly, Putnam and the creature are never seen together in an establishing shot) and grotesque, a faceless creature with translucent skin, exposed veins, thick patches of matted fur and, if that were not enough, one single unblinking eyeball in the centre of his otherwise featureless face. Even the limitations of black-and-white cinematography do not spare us; "It" is absolutely hideous. Putnam takes a good look and suddenly his eyes widen and his mouth opens $\because \quad$ as if to scream. Backing away, he averts his eyes and covers his face, just as the film immediately cuts to a close-up of a hand repeatedly slamming on a car horn. The horn, of course, is Putnam's scream, or, rather, the scream that never was. Arnold permits us to see the face of male fear without hearing the accompanying shriek that would tarnish Putnam's image as an unrelenting man of science. To remain credible - to the viewer, to his sweetheart, his colleagues, and even himself-Putnam must maintain absolute objectivity, swallow his emotions, and keep his mouth shut. Thus, we are treated to a male scream displaced onto an inanimate object, the car, that potent symbol of 1950s modernity, progress, and development that, as Marling writes, "was the new Conestoga wagon on the frontier of consumerism, a powerful instrument of change, a chariot of fiery desire"(135). Importantly, as Marling reveals, the 1950s automobile was gendered, seen as man's other female companion that, in addition to his wife, home, and television set, rounded out the critical components of the American Dream. "The typical American male looked upon the convertible as a mistress," Marling proclaims, attesting to the powerful imagery enforced by ad copy that linked consumer fantasies to masculine prowess 
(138). In this way, Putnam's scream, abrasively emitted from a car horn, is displaced onto the female (auto) body, a distinctly appropriate outlet for such an outburst from a male hero.

Gordon Douglas's Them! further illustrates this tendency for science fiction film to avoid showcasing leading men succumbing to weakness, but not without an intriguing twist. Bill Warren argues that Them! includes a most likely unintentional narrative oddity uncommon for science fiction films of the decade. That is, while the main characters, police sergeant Ben Peterson (James Whitmore) and FBI agent Robert Graham (James Amess) both function as male leads, neither of them alone is the obvious hero. Warren's choice for leading man lies with Peterson because of his "low key masculine likeability" and his "craggy charm" in addition to his character's prompt introduction at the start of the film (Graham's is strangely delayed until much later), all of which tip the scales of audience sympathy in his favour (193). Warren's logic, however, while not without merit, ignores the fact that it is Arness's character who survives until the end. Interestingly, both men cry out in fear in the film. In opposition to Warren's view, I argue that it is the specific nature of Peterson's scream that signals his character's secondary status in the film, making Graham the hero and thus reinforcing the imperative that real men do not scream like women, they shout like men.

Them! follows the attempts of the New Mexico police department, the FBI, and the US Air Force as they try to contain and destroy an army of gargantuan ants (the product of radioactive fallout from early atomic testing) before the queens lay more eggs, the colony repopulates, and the massive insects destroy civilization. In the final moments of the film, Peterson is strangled by a giant ant just after he helps rescue two young boys trapped beneath the city in the Los Angeles storm drains. As the ant nearly rips him in two, his face registers fear and anguish and he screams out over a half dozen times (several of these sounds are stock effects, a 
point to which we will return to below). Signalling his utter helplessness in the clutches of the enormous insect poisoning him with venom, his screams are high-pitched shrieks suggestive of Chion's female scream that function as a cry heard in the face of death. Peterson dies in the drains shortly thereafter, just as backup arrives. As Douglas would have it, Graham also screams but his single shout is more aptly described as what Chion views as a "bestial" call, one existing in a different league than the female "screaming point" (78). As Graham attempts to shoot another ant in the drains, his gun stalls and the ant scurries near. Graham fiddles with his weapon and looks up to find himself face-to-face with the oversized insect. He screams; or, rather, he yells. Indeed, we hear Graham cry out, but his vocalization registers an octave lower than Peterson's scream from a moment earlier, more along the lines of Chion's masculine demarcation of territory than a feminine lapse into "the exit of being" (79). Graham's shout is precisely an exhibition of his power and strength; he narrowly avoids the ant's attack and fires away at the menacing creature until it collapses in the drains. As demonstrated by Peterson's screams and death, his is a character who must die as punishment for showcasing feminized fear. It is Graham's survival precipitated by a masculine shout of authoritative commanding and conquering, coupled with Peterson's demise-foreshadowing scream, that marks him as the actual hero of the film (a fact unrecorded and unheralded by Arness's low billing). At the end of Them!, so it would seem, it is calm and collected masculine authority which perseveres. Indeed, the best man won.

\section{It Scared the Life out of Him!}

Menacing creatures in science fiction rarely distinguish between men and women when they launch an all-out attack on humanity, and both genders provide equal opportunity for hungry radioactive monsters on the loose in small-town Middle America. Men do scream in 
science fiction, but as exceptions to the rule a caveat pertains to them. Screaming men are rarely, if ever, heroes or leading men but are instead bumbling scientists (Tarantula), generic military men (Them! It Conquered the World), Soviet spies (The Flying Saucer), police officers (Tarantula), county sheriffs (It Came from Beneath the Sea, It Conquered the World), rocket ship engineers (Forbidden Planet), ranch hands (Tarantula), sailors (Them!), and other minor characters whose sole existence in the plot is to fulfill one purpose: to be eventually killed off in climactic moments. These men are most likely to scream, cry out, or shout, and their existence is doomed from the start. Their sudden deaths alleviate their gender role reversal in the moment when they open their mouths and scream like women; a gruesome demise is only fit punishment for such a transgression. Given that the underlying message of these films leans towards an obsession with success on behalf of the American government and military (a good many of which often code the alien as a thinly-veiled euphemism for Communists or Soviet infiltrators), inclusion of male characters who are introduced into the story merely to be brutally killed suggests that in order for there to be a hero, someone must be the loser.

Jack Arnold's Tarantula and its inspiration, Them!, both feature these types of screaming men. Well into Tarantula, the colossal title monster frightens a group of horses on a desert ranch, prompting an unnamed (and uncredited) rancher to investigate with rifle in tow. The rancher's attempts to shoot the beast are predictably in vain and, as the spider closes in on him, we see the tiny man from the point of view of his attacker moments before he is killed. As the shadow of the beast closes in on him, we hear him emit high-pitched shrieks, and that is the last we hear of him. Shortly thereafter, two state police officers (again, unnamed and uncredited) are parked on the highway, determined to kill the spider who is advancing rapidly toward them. Like the rancher's, their attempts to shoot at the giant spider are spectacularly unsuccessful and, when they return to 
their vehicle to flee the imminent danger, their car will not start (again, their end is nigh). A second time, we watch from the spider's perspective as it moves in on its prey: one of the officers barely manages to open the car door and, as he looks up into the face of death (that is, directly into the lens), he screams just as furry legs move on top of him. In an analogous scene not far from the beginning of Them!, police officer Ed Blackburn is left alone to rummage for clues in the ruins of Gramps Johnson's store in the latest investigation involving a string of mysterious deaths and disappearances in the New Mexico desert. Howling winds and shrill insect squeals provide sinister accompaniment to Blackburn's search of the store's dark and shadowy exterior. As he disappears from frame with gun in hand, shots are suddenly fired, the squeals become louder, and a man's voice cries out in a scream. Darkness momentarily overcomes the frame as a cacophony of strange noises overwhelms our ears and we know that Blackburn will not retum alive. In both films, the screaming man is a minor character introduced as bait for the big bug; his death (as predicted by his own scream) illustrates the power and brute strength exhibited by the horrific creatures that must be captured, contained, and destroyed.

Films featuring a single screaming woman (This Island Earth, War of the Worlds, The Man from Planet X. The Day the Earth Stood Still. Invaders from Mars, Invasion of the Body Snatchers) treat the female scream as a climactic moment signalling an instance where the body is in crisis (a condition which, in 1950s science fiction, seems always to be affecting women), one which is ultimately resolved when the woman flees, is rescued by the hero, or is made safe by some other circumstance which renders the provocation of her scream no longer harmful or dangerous. The visual and aural spectacle of the female scream thus points to uncertain danger, but typically does not predict a gruesome death for a female character. In contrast, as illustrated in Tarantula and Them!, the male scream foreshadows a minor character's final moments in the 
narrative right before he is tortured, bitten, ravaged, stung, or eaten. The male scream, then, is not accorded the same type of prominence in the film, for the characters who scream are unknowns without personalities, nobodies in whom we are not invested. Their screams are brief and fleeting as opposed to the long and drawn out screams of female heroines, wherein the score, cinematography, and overall mise-en-scène all contribute to a gradual build up of terrifying suspense in the moments just before a tight close-up features the woman as she opens her mouth in a shriek. Consequently, the female scream points to momentary narrative ambiguity that will be safely resolved whereas the male scream is a factual statement of unrelenting horror so catastrophic even man's best efforts cannot contain it. According to these conventions, in the end it is she who is rescued while he is left to die. What we see here, in Tarantula and Them! and other films from the genre, is that one may only get away with screaming if one is a woman, for the assumption of feminine frailty is so entrenched that it must be safeguarded, protected, and even encouraged. This assumption is so great that it leads scholars like Chion and Sjogren to assert that men do not scream at all, an argument which suggests that in those instances when men do scream like women, they somehow become women. This, of course, is such a grave misstep that it may only be resolved in one way: kill him off, and let a "real" man save the day. Interestingly, the men who scream in Them! and Tarantula do so in response to (and are eventually destroyed by) earth-bound creatures produced as a result of human interference with nature, creatures which are exemplary of Creed's notion of the monstrous-feminine that exist within the horror genre. Such feminine monstrosities are created within these two films as a result of the male-dominated realm of science run amok, and surface frequently in science fiction-horror hybrid films. The presence of these types of creatures parallels the "monstrous masculine" aliens from outer space who provoke screams of terror from frightened heroines 
discussed earlier in such films as The Man from Planet X, The Day the Earth Stood Still, and This Island Earth. In both sets of films, the provocations of both male and female screams are symbolically rooted in the fear of sexual difference, emerging especially in relation to confrontations with the archaic mother, the seeping female body, and uncontrollable or ambiguous male sexual desire.

\section{The Sound of the Man Screaming... Or Is It?}

Just as it is the case that male and female screams function differently within with the science fiction milieu, male screams also look and sound much different than their female counterparts. The female scream is one of pomp and circumstance, a filmic event in and of itself, a genuine narrative crisis which must be accorded significant time and attention. Such screams are usually vocalized by heroines, characters in which we are heavily invested and whose survival is most certainly guaranteed. The face of the screaming woman is often shown either in a medium shot or close-up, with careful attention paid to capturing the contrast between the stark whites of her eyes and her ruby red lips (a distinction which seems noticeably apparent even in black and white films), lips which open to scream just as readily as they part to kiss the hero who rescues her. The male scream, in contrast, is short and fleeting, a brief interlude of danger which propels the plot forward but remains largely inconsequential in terms of both how it is framed and the outcome of the character who voices it. In addition to being a minor character of little significance, the screaming man rarely faces the camera and if he does his face is rarely, if ever, featured in a close-up. After his inevitable death, he is quickly forgotten. It may also be said that male and female screams also sound different as a result of all these factors; again, the male scream reeks of insignificance. 
Well into Them!, a short scene cuts to two men at sea onboard a sugar-bearing cargo ship predictably overrun by giant ants. As one sailor furiously sends S.O.S messages from inside the cabin, another is shown firing a pistol at a swarm of ants. Within seconds of each other, both men are grasped in the mouths of the enormous ants, two male screams are heard, and the scene dissolves. Later, during the film's final moments as military troops clear a pathway through the Los Angeles underground sewer system, a ceiling collapses and falling rubble crushes one of the men. We hear him scream as he disappears beneath the debris and, curiously, his scream sounds familiar. In fact, it sounds exactly like the scream of the man sending the S.O.S. message earlier (who is by now dead) and we will hear it yet again when Peterson is dismembered by an ant after rescuing the two boys. The screams of these three men are not produced using their own voices but instead take advantage of an effect known as the Wilhelm scream.

The Wilhelm scream, a stock sound effect of a man screaming in horror recorded by character actor and musician Sheb Wooley, was first introduced in the 1951 film Distant Drums during a scene in which a man is bitten by an alligator and dragged underwater into a river (Lee). The scream takes its name from its second appearance in the notable 3D Western, The Charge at Feather River (1953), in which a minor character, Private Wilhelm (Ralph Brooks), is struck in the leg with an arrow and his voice is dubbed with the sound effect (Lee). Throughout the 1950s and 60 s, the Wilhelm scream was used frequently in a wide variety of further Wamer Bros. productions, taken out of the studio's sound archives and used as a stock sound for male characters in distress, pain, or danger. It has since become legendary for its inclusion in over 150 films (in addition to countless television shows, cartoons, and video games) over the last sixty years, including the hit blockbuster franchises $\underline{\text { Star Wars }}(1977,1980$, and 1983) and Indiana Jones $(1981,1984,1989)$. The inclusion of the Wilhelm scream in each of the films in these two 
successful trilogies was initially something of a running gag among the sound engineers working on them, a gag which has since spread in the Hollywood sound community and fuelled its continued popularity to the present day (Lee).

At the time when Them! (one of Warner Bros.' most successful sci-fi outputs during the decade) was filmed, the Wilhelm was not the in-joke among sound editors it is today. Given that it was only three years after its initial recording and use in Distant Drums, the use of the Wilhelm scream in Them! can be assumed to have been an effort to capitalize on the availability of the extensive Warner Bros. audio library, thereby lowering production costs. That said, the insertion of the Wilhelm scream multiple times in Them! is not merely one of arguable convenience on part of the sound editors, but also functions to render voiceless and interchangeable the male characters who are aurally linked to it, whose deaths are not paired with their own voices but are instead overdubbed with a stock effect. Both the presence of the Wilhelm scream in Them! and the substitution of a male scream for a car hom in It Came from Outer Space complicate the relation between audible sound and its visible source by displacing the authentic voice of male fear, instead privileging a mechanized sound.

It is also significant to point out that all three of the male characters whose voices are dubbed over with the Wilhelm scream in this film are not actually seen screaming. Instead, their faces are turned away from the camera at the moment in which the sound effect is inserted. Given the difficulty of syncing the male actor's facial movement to a stock sound effect in postproduction, the choice to sync the sound to footage of the men as their faces are turned away is not unsurprising. Nevertheless, this audio choice only further upholds the underlying presumption that male fear cannot be directly shown, but can only be indirectly heard through an asynchronous stock sound effect. In contrast to the screaming women who emerge in other films, 
the screaming men in Them! are only ever seen from behind, their faces obscured by oversized ant limbs. Unlike the tight close-ups of the screaming woman-wherein the visual signifiers of the gaping mouth, the paralysis of the face, and the widened eyes are just as, if not more, important as the sound of the scream itself-the screaming men in Them! face away from the camera, their screams signalling impending doom of nameless, faceless characters of little importance to the overall film. Thus, while the screaming woman is precisely the kind of spectacle Williams discusses, embodying emotion and excess right at the moment of "gross-out horror" ("Film Bodies" 4), the screaming man, it would seem, is a nobody.

\section{The Universality of Female Fear}

Science fiction films of the 1950 s played with the possibility of social change by featuring a large number of independent female scientists whose masculinized first names (often shortened from longer, more feminine names) confirmed their status as "one of the boys." Yet, if science fiction permitted women to engage as equals in various male-dominated workplaces such as laboratories, rocket ships, and wide-open desert landscapes-at least before they married and assumedly stepped down from those positions following the end credits - sci-fi also conformed to traditional models of gender that favoured female characters who cower meekly when presented with danger. In countless films, it is the independent career-minded female scientist who cries out when confronted with an alien, mutant, robot, or giant insect, a woman who moments ago was among the most articulate and sound-minded of the group. Women in these films may be scientists, objective and rational, and yet they are still women who-according to genre conventions - are ultimately weaker and more fragile than their male co-workers and seemingly have no choice but to scream when confronted with a frightening scene. Indeed, in Them! Pat (Patricia) Medford (Joan Weldon) is the first in an all-male group of scientists and 
local police officers to see one of the giant ants appear from behind a sand hill. She screams loudly before tripping and falling face-first into the sand, a reaction that provokes the other men around her to shoot the enormous insect until it dies. Medford's scream, however, scems out of place because the next shot is of her sitting calmly and without fear in the sand a safe distance away, watching the battle. This contradiction in Medford's emotions-screaming one moment, cool and collected the next-illustrates the final and most important of the sci-fi scream conventions, namely that the female scream is an articulation not merely of resolutely female fear (and hence indicative of so-called "natural" passive or otherwise delicate femininity) but, more importantly, of universal fear. Out of the mouths of women bursts forth the embodiment of all of our fears. As Williams pointed out, the female body is that of spectacle and excess in classical Hollywood cinema, so of course it is the case that leading men do not scream; they do not have to, because she does it for them. As illustrated with the car horn honking in It Came from Outer Space, male fear is displaced onto a female embodiment in order to permit fear to exist without questioning the stoic rationality of 1950 s masculinity.

Both Sjogren and Chion agree that the scream is undeniable feminine, for men rarely ever scream. As we have seen in the science fiction genre, however, this is not necessarily the case, for men do scream, and their screams emerge in disturbingly violent scenes. Sjogren's definition of the female scream as representing "a body's (impending) mutilation, and, subsequently, the female character's subjective disappearance from the film text" (78), aptly describes the screaming man in science fiction as well as it describes the screaming woman. The screaming man is never a hero, however. A closer look at several minor male characters in Them! and Tarantula reflects a larger trend within the genre, demonstrating that acquiescence to fear is a transgression on behalf of the screaming man. As such, his fate is duly sealed with his 
disappearance from the film in the form of a gruesome end. Female characters are permitted to scream and survive the terrors that provoke them while screaming men must be punished with an untimely death, serving as a grave warning to dangers for inappropriate expressions of (feminine) emotion. In killing off the screaming man, the narrative suggestion is that one should "man up" and win the battle rather than cower like the woman one is supposed to be protecting. And so we return again to the screaming woman, as it is she who screams for all of us. If male heroes never scream and non-leading screaming men are silenced by death, it is she who remains at the forefront of the film and gives a voice to that moment of terror which overcomes us just as the worst is about to strike. It is thus the screaming woman who confirms and confronts the most unimaginable horrors in a most spectacular and satisfying way. It is she who embodies the excesses of emotion, vocalization, and bodily convulsions that thrill us. 


\section{Conclusion: The Voice and the Void}

While the female scream still remains a filmic convention in the ways it was codified in the classical Hollywood era, its execution has certainly been expanded to reveal new expressions of gendered subjectivity in the decades to follow. The science fiction remake has much to offer by way of revealing these changes.

Jack Finney's 1955 novel about mysterious pod people seeking control over innocent humans has been the subject of three cinematic adaptations, with the first and the third featuring drastically different representations of the female scream. In Don Siegel's Invasion of the Body

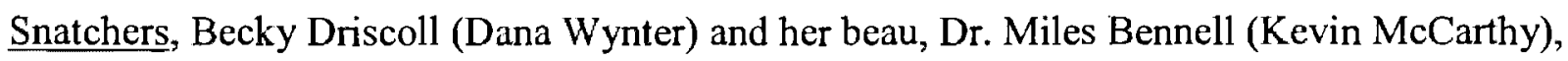
upon realizing the truth of their town's takeover by demonic pods, attempt to maintain a low profile before making their escape to safety. They mimic the behaviour of the pods by displaying little emotion and exhibiting few facial expressions in order to maintain the illusion that they have already been "taken over." The pods are convinced until Becky is surprised at the sight of a dog being run over in the middle of the street. As other pods look on with disinterest, Becky suddenly blurts out a loud high-pitched scream, effectively revealing that she is human and singling her out as such to the emotionless and predatory pod people. Now aware of her presence, the pods chase after her and Miles in the hopes of converting the last of the remaining humans into mindless drones. In the end she is doomed, given away by her own scream - the sole expression of her humanity.

In Body Snatchers (1993), Abel Ferrara's take on Finney's novel, the scream is transformed from an instinctual human response to harm into the alerting cry used by the pods to indicate discovery of an unconverted human to the others. Upon discovering that his wife, Carol Malone (Meg Tilly), has become a pod, Steve Malone (Terry Kinney) and his two children flee 
their house in the middle of the night, but not without Carol on their trail. As she looks out of doorway of the family home and watches the three of them run out into the street, Carol purposefully raises a pointed finger towards centre frame, looks directly into the camera with wide eyes and an open mouth and lets out a piercing scream. Or, rather, she opens her mouth and lets in multiple screams. In Ferrara's version of Finney's tale, Carol's haunting scream is comprised of the sound of numerous voices echoing and overlapping with the shimmer of wind chimes, a chorus of shrieks which seem to be simultaneously ejected from and pulled into her body. Within seconds, dozens of pods flood the streets from neighbouring homes, summoned to take up the chase of their latest victims. In Body Snatchers, Carol's scream is the voice of the collective united together as they mercilessly invade the population. Her scream is communicative, a sound which is understood by the pods and is an incitement to action. Carol's articulation of the scream stands in opposition to the incomprehensible shriek of fear of Becky Driscoll and other screaming women from the 1950s. In Ferrara's post-feminist remake, the female scream is a sound which communicates female agency rather than weakness, as was common of films from the previous generation. Comparing these two scenes, each based on the same source material but executed nearly forty years apart, illustrates how filmic conventions can transform over time to reflect changing cultural values.

Consequently, in light of the pervasive ideologies that operated to align traditional models of gender with anti-Communist national enterprise in postwar America, the 1950s science fiction scream is suggestive of much larger issues beyond the immediate fear of an alien or robot from another world. In sci-fi, when the woman screams a whirlwind of emotional excesses begin to emerge. Her scream is a rallying cry against the culturally-sanctioned restrictions of the era which limit her autonomy and confine her to the home in spite of her 
budding higher aspirations. The scream acutely expresses fear of the inability to control her desires and keep them within the confines of the marital realm, a fear conditioned by the resulting social ostracism such unleashed desires would provoke. Her scream signals her need for male protection and its guarantees of financial, emotional, and social security, regardless of whether or not that is what she truly wants or needs. And, lastly, her scream is the sole weapon she has to ward off the malicious creature or disaster confronting her, one that is not entirely effective considering the severe restrictions placed on her by her male colleagues or peers, including the doubts of her abilities based solely on the fact that she is a woman.

The voice of the screaming woman, then, is a familiar cinematic convention but it is also much more. Her voice is that of American women in the 1950s: of mothers, daughters, sisters, girlfriends, and wives, many of whom struggled to negotiate these social contradictions and find the words to convey the nature of their disenfranchisement. "The Woman Question," as it was called by radical left-leaning American Communist Party members in the 1930s and 40s, would be abandoned immediately following the war as anti-Red rhetoric set in. It would not be until years later that the status quo would be questioned so publicly and with such unyielding fervor as in Betty Friedan's The Feminine Mystique (1963), a book which, as May writes, “enabled discontented women to find their voices" and "revive the vision of female independence that had been alive before World War II" (209). Until Friedan's views were to overtake the nation in the early to mid-1960s - a time which also coincided with the decline of the golden era of science fiction in the form it was popularized in the fifties-the problems facing women would go largely unnamed. During the $1950 \mathrm{~s}$, the science fiction scream was a fitting metaphor for some of the many tensions emerging from beneath the surface of mid-twentieth century American 
culture, an incomprehensible speech act that stood for the reality and experience which could be neither directly stated nor shown in relation to white middle-class female experience.

The science fiction monster, alien, or mutant, far from being a cheap gimmick to lure hormonal teenagers into drive-in lots or thinly-veiled political commentary alluding to Communist threats to national security, reflects precisely the gender panic and confusion surfacing during a decade so dedicated to making life faster, cheaper, and easier. The nonhuman creatures in The Man from Planet X, The Day the Earth Stood Still, and This Island Earth serve as distorted reflections of the paradigms of masculinity women were confronted with during this time. Without her being able to discern the intentions of these mute beings from other worlds, a woman's scream seemed the only appropriate response, one which not only further exacerbated the equation of femininity with weakness and emotional frailty but also enforced the strict lines drawn between femaleness and male/alien Otherness. Men who screamed in films such as Them! and Tarantula were to be erased from the narrative while stoic heroes featured in titles like It Came from Outer Space would be exalted, thereby enforcing masculine dominance, authority, and heroic displays of violence in the name of restoring order to American society and effectively punishing any expression of masculinity which failed to maintain these gendered imperatives. As these films and many others in the genre demonstrate, the look and sound of male and female screams in 1950s American science fiction film reflected and upheld the binary model of gender as sanctioned by experts, public policy, and many forms of popular culture. By the end of the golden era of science fiction, as the anxieties of the 1950s relaxed into the radical decade of the swinging sixties, such screams would no longer go unheard. 


\section{Works Cited}

Baxter, John. Science Fiction in the Cinema. New York: A.S. Barnes \& Co., 1970.

Belton, John. "Technology and Aesthetics of Film Sound." Film Sound: Theory and Practice. Ed. Elizabeth Weis and John Belton. New York: Columbia University Press, 1985. 6372.

Brophy, Phillip. "I Scream in Silence: Cinema, Sex and the Sound of Women Dying." Cinescope: The World of Sound in Film. Ed. Phillip Brophy. Sydney: Southwood Press, 1999.

Calvacanti, Alberto. "Sound in Films." Film Sound: Theory and Practice. Ed. Elizabeth Weis and John Belton. New York: Columbia University Press, 1985. 98111.

Chion, Michel. The Voice in Cinema. Ed. and trans. Claudia Gorbman. New York: Columbia University Press, 1999.

Cornea, Christine. Science Fiction Cinema: Between Fantasy and Reality. Edinburgh: Edinburgh University Press, 2007.

Creed, Barbara. "Horror and the Monstrous-Feminine: An Imaginary Abjection." Feminist Film Theory: A Reader. Ed. Sue Thornham. Edinburgh: Edinburgh University Press, 1999. 251-66.

Doane, Mary Ann. "The Voice in the Cinema." Film Sound: Theory and Practice. Ed. Elizabeth Weis and John Belton. New York: Columbia University Press, 1985. 162-76.

Hrvatin, Emil. "The Scream." Performance Research: Letters from Europe. Ed. Richard Gough. Volume 2, No. 1. London: Routledge, 1997. 82-91.

Kawin, Bruce. "Children of the Light." The Dread of Difference: Gender in the Horror Film. Ed. Barry Keith Grant. Austin: University of Texas Press, 1996. 324-45.

Lee, Steve. "Sound Effects: The Wilhelm Scream." Hollywood Lost and Found. $<$ http://www.hollywoodlostandfound.net/wilhelm/index.html $>17$ May 2005. Accessed 8 February 2010.

Lev, Peter. History of the American Cinema: Transforming the Screen, 1950-1959. New York: Charles Scribner's Sons, 2003.

Marling, Karal Ann. As Seen on TV: The Visual Culture of Everyday Life in the 1950s. Cambridge: Harvard University Press, 1994.

May, Elaine Tyler. Homeward Bound: American Families in the Cold War Era. New York: 
Basic Books Inc., 1988.

Nama, Adilifu. Black Space: Imagining Race in Science Fiction Film. Austin: University of Texas Press, 2008.

Noonan, Bonnie. Women Scientists in Fifties Science Fiction Films. Jefferson: McFarland \& Company, 2005.

O'Donnell, Victoria. "Science Fiction Films and Cold War Anxiety." History of the American Cinema: Transforming The Screen, 1950-1959. Ed. Peter Lev. New York: Charles Scribner's Sons, 2003. 169-96.

Pomerance, Murray. "Introduction: Movies and the 1950s." American Cinema of the 1950s: Themes and Variations. Ed. Murray Pomerance. New Brunswick, N.J.: Rutgers University Press, 2005. 1-20.

Sobchack, Vivian. Screening Space: The American Science Fiction Film. New Brunswick, N.J.: Rutgers University Press, 1997.

--.. "The Virginity of Astronauts: Sex and the Science Fiction Film." Alien Zone: Cultural Theory and Contemporary Science Fiction Cinema. Ed. Annette Kuhn. London: Verso, 1990. 103-15.

Sontag, Susan. "The Imagination of Disaster [1965]." Against Interpretation and Other Essays. New York: Picador, 1990. 209-62.

Sjogren, Britta. Into the Vortex: Female Voice and Paradox in Film. Urbana and Chicago: University of Illinois Press, 2006.

Susman, Warren. "Did Success Spoil the United States? Dual Representations in Postwar America." Recasting America: Culture and Politics in the Age of the Cold War. Ed. Lary May. Chicago: University of Chicago Press, 1989. 19-37.

Tarratt, Margaret. "Monsters from the Id." The Dread of Difference: Gender in the Horror Film. Ed. Barry Keith Grant. Austin: University of Texas Press, 1996. 346-65.

Telotte, J.P. Science Fiction Film. Cambridge: Cambridge University Press, 2001.

Vieth, Errol. Screening Science: Contexts, Texts, and Science in Fifties Science Fiction Film. Lanham, MA: Scarecrow Press, 2001.

Warren, Bill. Keep Watching the Skies: American Science Fiction Movies of the Fifties. Volume 1: 1950-1957. Jefferson: McFarland Classics, 1982.

Weis, Elisabeth. The Silent Scream: Alfred Hitchcock's Sound Track. Rutherford, N.J.: Fairleigh Dickinson University Press, 1982. 
Weis, Elisabeth and John Belton, Eds. Film Sound: Theory and Practice. New York: Columbia University Press, 1985.

Williams, Linda. "Film Bodies: Gender, Genre, Excess." Film Quarterly 44:4 (Summer 1991) 2-13.

---. "When the Woman Looks." The Dread of Difference: Gender in the Horror

Film. Ed. Barry Keith Grant. Austin: University of Texas Press, 1996. 15-34.

Wood, Robin. "An Introduction to the American Horror Film." Movies and Methods Volume II. Ed. Bill Nichols. Berkeley: University of California Press, 1985.

Young, William H. and Nancy K Young. The 1950s. Westport: Greenwood Press, 2004. 


\section{Filmography}

Attack of the Puppet People (Bert I. Gordon, Alta Vista Productions, 1958)

Barbarella (Roger Vadim, Dino de Laurentiis Cinematografica, 1968)

Beast with a Million Eyes, The (David Kramarsky, San Mateo Productions, 1955)

Beast from 20,000 Fathoms, The (Eugène Lourié, Jack Dietz Productions, 1953)

Blob, The (Irwin S. Yeaworth, Fairview Productions, 1958)

Body Snatchers (Abel Ferrara, Warner Bros. Pictures, 1993)

Charge at Feather River, The (Gordon Douglas, Warner Bros. Pictures, 1953)

Creature from the Black Lagoon, The (Jack Amold, Universal International Pictures, 1954)

Day the Earth Stood Still, The (Robert Wise, Twentieth Century-Fox Film Corporation, 1951)

Deadly Mantis, The (Nathan Juran, Universal International Pictures, 1957)

Destination Moon (Irving Pichel, George Pal Productions, 1950)

Distant Drums (Raoul Walsh, United States Pictures, 1951)

Earth vs, the Flying Saucers (Fred. F. Sears, Clover Productions, 1956)

Flying Saucer, The (Mikel Conrad, Colonial Productions, 1950)

Forbidden Planet (Fred McLeod Wilcox, Metro-Goldwyn-Mayer, 1956)

Fly, The (Kurt Neumann, Twentieth Century-Fox Film Corporation, 1958)

Incredible Shrinking Man, The (Jack Arnold, Universal International Pictures, 1957)

Invaders from Mars (William Cameron Menzies, National Pictures, 1953)

Invasion of the Body Snatchers (Don Siegel, Walter Wanger Productions, 1956)

Invasion of the Saucer Men (Edward L. Cahn, Malibu Productions, 1957)

Invisible Boy, The (Hermann Hoffman, Metro-Goldwyn-Mayer, 1957)

It Came from Beneath the Sea (Robert Gordon, Clover Productions, 1955) 
It Came from Outer Space (Jack Arnold, Universal International Pictures, 1953)

It Conquered the World (Roger Corman, Sunset Productions, 1956)

Man from Planet X, The (Edgar G. Ulmer, Sherrill C. Corwin Productions, 1951)

On the Beach (Stanley Kramer, Stanley Kramer Productions, 1959)

Project Moon Base (Richard Talmadge, Galaxy Pictures Inc., 1953)

Psycho (Alfred Hitchcock, Shamley Productions, 1960)

Rocketship X-M (Kurt Neumann, Lippert Pictures, 1950)

Tarantula (Jack Arnold, Universal International Pictures, 1955)

Them! (Gordon Douglas, Warner Brothers Pictures, 1954)

Thing from Another World, The (Christian Nyby, Winchester Pictures Corporation, 1951)

39 Steps, The (Alfred Hitchcock, Gaumont British Picture Corporation, 1935)

This Island Earth (Joseph F. Newman, Universal International Pictures, 1955)

20 Million Miles to Earth (Nathan Juran, Morningside Productions, 1957)

War of the Worlds (Byron Haskin, Paramount Pictures, 1953)

When Worlds Collide (Rudolph Mate, Paramount Pictures, 1951) 